\title{
Labiobaetis Novikova \& Kluge in West Africa (Ephemeroptera, Baetidae), with description of a new species
}

\author{
Thomas Kaltenbach ${ }^{1,2}$, Jean-Luc Gattolliat ${ }^{1,2}$ \\ I Museum of Zoology, Palais de Rumine, Place Riponne 6, CH-1005 Lausanne, Switzerland 2 University of \\ Lausanne (UNIL), Department of Ecology and Evolution, CH-1015 Lausanne, Switzerland \\ Corresponding author: Thomas Kaltenbach (thomas.kaltenbach@bluewin.ch) \\ Academic editor: K. Williams | Received 23 February 2021 | Accepted 25 March 2021 | Published 27 April 2021 \\ http://zoobank.org/D6289103-A48D-43EB-B3B9-4C77182BCB58 \\ Citation: Kaltenbach T, Gattolliat J-L (2021) Labiobaetis Novikova \& Kluge in West Africa (Ephemeroptera, Baetidae), \\ with description of a new species. African Invertebrates 62(1): 355-382. https://doi.org/10.3897/AfrInvertebr.62.64885
}

\begin{abstract}
Material collected between 1984 and 1988 in Guinea and Mali and between 2003 and 2008 in the Ivory Coast substantially increased our knowledge of Labiobaetis Novikova \& Kluge in West Africa. We identified eight different species using morphological characters. One species, L. ediai sp. nov., is new to science; it is described and illustrated, based on its nymphs. The status of L. boussoulius (Gillies, 1993) is discussed and the divergent morphology of L. elouardi (Gillies, 1993) is compared to other species of Labiobaetis. A key to the nymphs of all West African species is provided and the distribution of Labiobaetis species in the Afrotropical realm is discussed.
\end{abstract}

\section{Keywords}

Afrotropical, COI, Gambia, Guinea, Ivory Coast, Mali, morphology

\section{Introduction}

The family Baetidae has the highest species diversity amongst mayflies, comprising ca. 1,100 species in 114 genera (updated from Sartori and Brittain 2015, Jacobus et al. 2019, Cruz et al. 2020), which is approximately one third of all mayfly species worldwide. They have a cosmopolitan distribution, except for New Zealand (Gattolliat and 
Nieto 2009). Investigations of the molecular phylogeny of the Order Ephemeroptera revealed the relatively primitive status of the family (Ogden and Whiting 2005; Ogden et al. 2009; Ogden et al. 2019).

The genus Labiobaetis Novikova \& Kluge, 1987, is one of the richest genera of mayflies with 145 previously described species (Barber-James et al. 2013; Kaltenbach et al. 2020 and citations therein; Kaltenbach and Gattolliat 2021). The distribution of Labiobaetis is nearly worldwide, except for the Neotropical realm, New Zealand, New Caledonia and some remote islands. The history and concept of the genus $\mathrm{La}$ biobaetis were recently summarised in detail (Shi and Tong 2014; Kaltenbach and Gattolliat 2018).

Recently, integrative taxonomy was applied on collections from the highly diverse regions of Southeast Asia and New Guinea, but also from Africa and many species were described and named (Kaltenbach and Gattolliat 2018, 2019, 2020a, 2021; Kaltenbach et al. 2020). The present contribution will focus on West Africa, which forms its own freshwater ecoregion as one of the five sub-regions of the Afrotropical realm (Barber-James and Gattolliat 2012: fig. 1).

The status of Afrotropical mayfly research was depicted by Barber-James and Gattolliat (2012). The history of taxonomic studies of Labiobaetis in the Afrotropical realm was briefly summarised in Kaltenbach and Gattolliat (2021). West Africa has a long history of mayfly research in general and many collections and studies were undertaken in that region. Between 1974 and 1989, the French ORSTOM (Office de la recherche scientifique et technique outre-mer), presently the IRD (Institut de Recherche pour le Développement), conducted field research in West Africa as part of an important onchocerciasis control programme (Lévêque et al. 2003). Aquatic macroinvertebrates were collected in about 100 localities, mainly in Guinea, Ivory Coast and Mali. Most localities were sampled regularly over a period of several years. As the systematics of aquatic insects was still poorly-known at the time, important alpha taxonomic research was conducted and several articles were published, including descriptions of new species and genera. The majority of mayflies known from West Africa were described, based on material collected during this programme (e.g. Elouard and Forge 1978; Gillies 1980, 1989, 1993, 1997; Elouard 1986a, b; Elouard and Gillies 1989; Elouard et al. 1990; Gillies and Elouard 1990; Elouard and Hideux 1991; Wuillot and Gillies 1993a, b, 1994; Gattolliat 2006; Gattolliat and Sartori 2006; Kaltenbach and Gattolliat 2020b), including three species of Labiobaetis (Gillies 1993). The present study is partly based on nymphs collected during the ORSTOM programme between 1984 and 1988 in Guinea, Ivory Coast and Mali. Another part of the material came from ecological studies done in the Ivory Coast 2003-2008 (Edia et al. 2015) (Fig. 1). Edia et al. (2015: tables 1, 2, fig. 1) also described the environmental characteristics and physical conditions of some of the river systems and a part of the sampling sites in the Ivory Coast (Rivers Ehania, Soumié, Eholié and Noé).

So far, only four species of Labiobaetis are known from West Africa: L. boussoulius (Gillies, 1993), L. elouardi (Gillies, 1993), L. gambiae (Gillies, 1993) and L. piscis Lugo-Ortiz and McCafferty, 1997 (Gillies 1993; Arimoro and Muller 2010). Here, we report four additional species from different West African countries, one of which is 


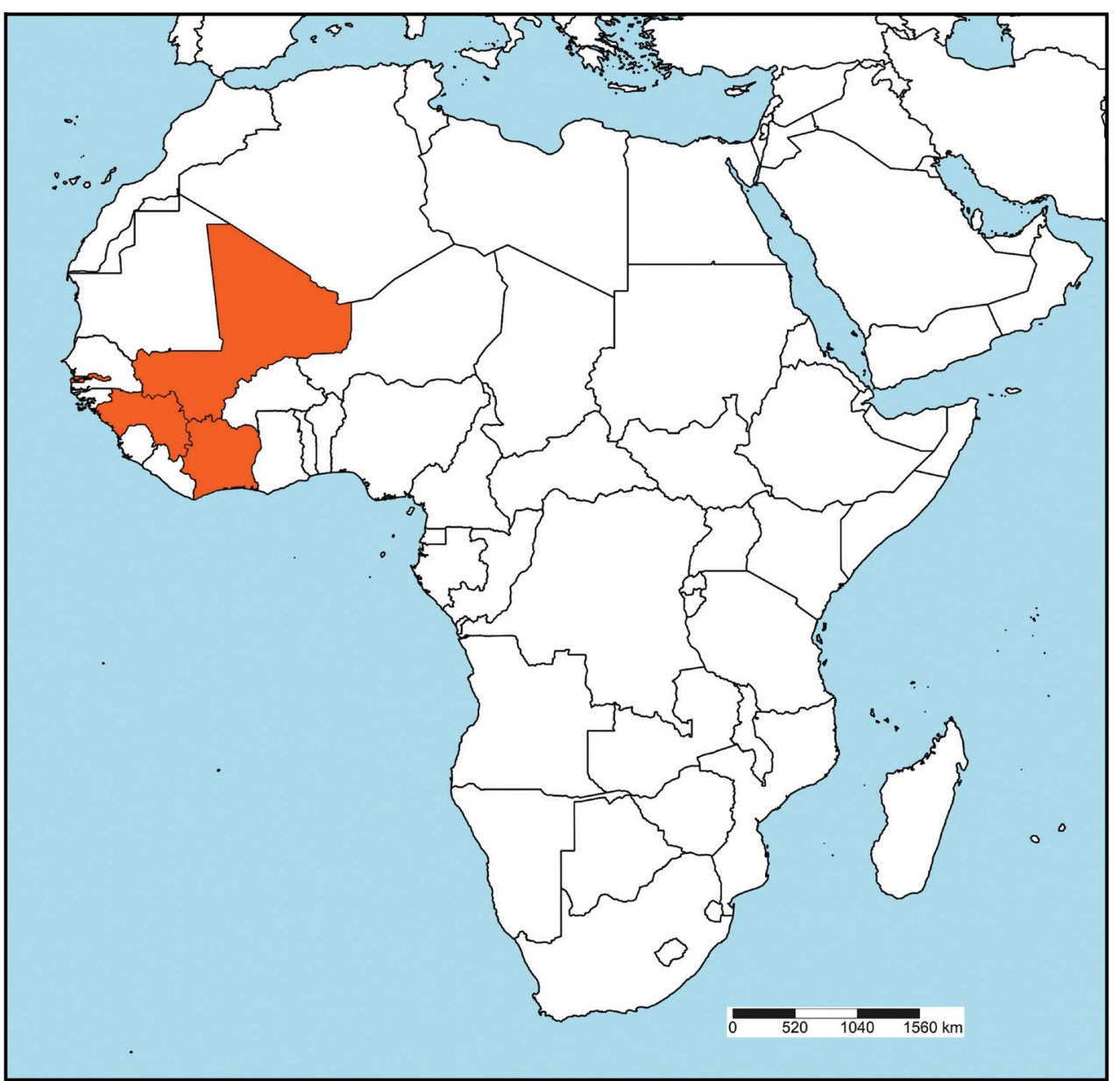

Figure I. Map of Africa with studied countries in red: Gambia, Guinea, Mali, Ivory Coast.

described and illustrated as a new species, based on nymphs (L. glaucus (Agnew, 1961), L. latus (Agnew, 1961), L. vinosus (Barnard, 1932) and L. ediai sp. nov.). The status of L. boussoulius is discussed below; the morphological particularities of L. elouardi are depicted and compared to other species in other realms. The total number of Labiobaetis species worldwide has now been increased to 146 .

\section{Materials and methods}

The specimens were collected between 1984 and 1988 in Guinea and Mali by JeanMarc Elouard (France) during the French ORSTOM programme for the control of onchocerciasis and between 2003 and 2008 in the Ivory Coast by Edia Oi Edia (Université Nangui Abrogoua, Abidjan, Ivory Coast), partly together with one of the authors (JLG). The nymphs were preserved in 70\%-96\% ethanol. 
Table I. Coordinates of locations of examined specimens (L. gambiae: localities Ivory Coast Eh1, Eh2, S1, E2, N2 from Edia et al. 2015, material not examined).

\begin{tabular}{|c|c|c|}
\hline Species & Locality & GPS coordinates \\
\hline L. boussoulius & Guinea: Boussoulé & $10^{\circ} 38^{\prime} 39^{\prime \prime} \mathrm{N}, 09^{\circ} 11^{\prime} 25^{\prime \prime W}$ \\
\hline \multirow[t]{7}{*}{ L. ediai sp. nov. } & Ivory Coast: Affiénou & $05^{\circ} 24^{\prime} 39^{\prime \prime N}, 02^{\circ} 55^{\prime} 43^{\prime \prime W}$ \\
\hline & Ivory Coast: Anoblékro & $05^{\circ} 29^{\prime} 44^{\prime \prime N}, 03^{\circ} 22^{\prime} 15^{\prime \prime W}$ \\
\hline & Ivory Coast: Banco & $05^{\circ} 23^{\prime} 17^{\prime \prime N}, 04^{\circ} 03^{\prime} 13^{\prime \prime W}$ \\
\hline & Ivory Coast: Goré & $06^{\circ} 22^{\prime} 28^{\prime \prime N}, 06^{\circ} 34^{\prime} 27^{\prime \prime W}$ \\
\hline & Ivory Coast: Grobiakoko & $05^{\circ} 51^{\prime} 18^{\prime \prime N}, 05^{\circ} 31^{\prime} 00^{\prime \prime W}$ \\
\hline & Ivory Coast: Pont Ehania & $05^{\circ} 16^{\prime} 42^{\prime \prime N}, 02^{\circ} 50^{\prime} 01^{\prime \prime W}$ \\
\hline & Ivory Coast: Pont Soumié & $05^{\circ} 24^{\prime} 53^{\prime \prime N}, 03^{\circ} 16^{\prime} 56^{\prime \prime W}$ \\
\hline \multirow[t]{2}{*}{ L. elouardi } & Guinea: Mt. Nimba & $07^{\circ} 46^{\prime} \mathrm{N}, 08^{\circ} 15^{\prime} \mathrm{W}$ \\
\hline & Ivory Coast: Banco & $05^{\circ} 23^{\prime} 17^{\prime \prime N}, 04^{\circ} 03^{\prime} 13^{\prime \prime W}$ \\
\hline \multirow[t]{14}{*}{ L. gambiae } & Gambia: Wali Kunda & $13^{\circ} 42^{\prime} \mathrm{N}, 15^{\circ} 07^{\prime} \mathrm{W}$ \\
\hline & Ivory Coast: Akakro & $05^{\circ} 28^{\prime} 36^{\prime \prime N}, 03^{\circ} 08^{\prime} 25^{\prime \prime W}$ \\
\hline & Ivory Coast: Boubo & $05^{\circ} 18^{\prime} 08^{\prime \prime N}, 04^{\circ} 22^{\prime} 37^{\prime \prime W}$ \\
\hline & Ivory Coast: Goré & $06^{\circ} 22^{\prime} 28^{\prime \prime N}, 06^{\circ} 34^{\prime} 27^{\prime \prime W}$ \\
\hline & Ivory Coast: Grobiakoko & $05^{\circ} 51^{\prime} 18^{\prime \prime} \mathrm{N}, 05^{\circ} 31^{\prime} 00^{\prime \prime W}$ \\
\hline & Ivory Coast: M'possa & $05^{\circ} 28^{\prime} 37^{\prime \prime N}, 02^{\circ} 51^{\prime} 30^{\prime \prime W}$ \\
\hline & Ivory Coast: Niambré & $05^{\circ} 52^{\prime} 46^{\prime \prime N}, 05^{\circ} 36^{\prime} 55^{\prime \prime W}$ \\
\hline & Ivory Coast: Pont Soumié & $05^{\circ} 24^{\prime} 53^{\prime \prime N}, 03^{\circ} 16^{\prime} 56^{\prime \prime W}$ \\
\hline & Ivory Coast: Riv. Ehania Eh1 & $05^{\circ} 24^{\prime} \mathrm{N}, 02^{\circ} 55^{\prime} \mathrm{W}$ \\
\hline & Ivory Coast: Riv. Ehania Eh2 & $05^{\circ} 17^{\prime} \mathrm{N}, 02^{\circ} 50^{\prime} \mathrm{W}$ \\
\hline & Ivory Coast: Riv. Eholié E2 & $05^{\circ} 23^{\prime} \mathrm{N}, 03^{\circ} 08^{\prime} \mathrm{W}$ \\
\hline & Ivory Coast: Riv. Noé N2 & $05^{\circ} 18^{\prime} \mathrm{N}, 02^{\circ} 46^{\prime} \mathrm{W}$ \\
\hline & Ivory Coast: Riv. Soumié S1 & $05^{\circ} 29^{\prime} \mathrm{N}, 03^{\circ} 22^{\prime} \mathrm{W}$ \\
\hline & Mali: Tienfala & $12^{\circ} 43^{\prime} \mathrm{N}, 07^{\circ} 44^{\prime} \mathrm{W}$ \\
\hline \multirow[t]{6}{*}{ L. glaucus } & Ivory Coast: Loc. Aboisso & $05^{\circ} 28^{\prime} 04^{\prime \prime N}, 03^{\circ} 12^{\prime} 26^{\prime \prime W}$ \\
\hline & Ivory Coast: Pont Soumié & $05^{\circ} 24^{\prime} 53^{\prime \prime} \mathrm{N}, 03^{\circ} 16^{\prime} 56^{\prime \prime W}$ \\
\hline & Mali: Kati-Kita & $12^{\circ} 44^{\prime} \mathrm{N}, 08^{\circ} 03^{\prime} \mathrm{W}$ \\
\hline & Mali: Missira & $13^{\circ} 48^{\prime} \mathrm{N}, 08^{\circ} 38^{\prime} \mathrm{W}$ \\
\hline & Mali: Sotuba & $12^{\circ} 39^{\prime} \mathrm{N}, 07^{\circ} 54^{\prime} \mathrm{W}$ \\
\hline & Mali: Tienfala & $12^{\circ} 43^{\prime} \mathrm{N}, 07^{\circ} 44^{\prime} \mathrm{W}$ \\
\hline \multirow[t]{10}{*}{ L. latus } & Guinea: Diani & $08^{\circ} 55^{\prime} 00^{\prime \prime} \mathrm{N}, 08^{\circ} 08^{\prime} 00^{\prime \prime} \mathrm{W}$ \\
\hline & Guinea: Férédougouba & $08^{\circ} 26^{\prime} \mathrm{N}, 07^{\circ} 10^{\prime} \mathrm{W}$ \\
\hline & Guinea: Kissidougou-Kankan & $09^{\circ} 19^{\prime} \mathrm{N}, 09^{\circ} 52^{\prime} \mathrm{W}$ \\
\hline & Guinea: Loffa & $08^{\circ} 27^{\prime} \mathrm{N}, 09^{\circ} 18^{\prime} \mathrm{W}$ \\
\hline & Guinea: N’Zébéla & $08^{\circ} 04^{\prime} \mathrm{N}, 09^{\circ} 05^{\prime} \mathrm{W}$ \\
\hline & Guinea: Sassambaya & $10^{\circ} 07^{\prime} 24^{\prime \prime N}, 09^{\circ} 44^{\prime} 06^{\prime \prime W}$ \\
\hline & Ivory Coast: Anoblékro & $05^{\circ} 29^{\prime} 44^{\prime \prime N}, 03^{\circ} 22^{\prime} 15^{\prime \prime W}$ \\
\hline & Ivory Coast: Grobiakoko & $05^{\circ} 51^{\prime} 18^{\prime \prime} \mathrm{N}, 05^{\circ} 31^{\prime} 00^{\prime \prime W}$ \\
\hline & Ivory Coast: Pont Ehania & $05^{\circ} 16^{\prime} 42^{\prime \prime N}, 02^{\circ} 50^{\prime} 01^{\prime \prime W}$ \\
\hline & Mali: Loc. Kati-Kita & $12^{\circ} 44^{\prime} \mathrm{N}, 08^{\circ} 03^{\prime} \mathrm{W}$ \\
\hline \multirow[t]{5}{*}{ L.piscis } & Guinea: Mt. Nimba & $07^{\circ} 46^{\prime} \mathrm{N}, 08^{\circ} 15^{\prime} \mathrm{W}$ \\
\hline & Ivory Coast: Anoblékro & $05^{\circ} 29^{\prime} 44^{\prime \prime N}, 03^{\circ} 22^{\prime} 15^{\prime \prime W}$ \\
\hline & Ivory Coast: Banco & $05^{\circ} 23^{\prime} 17^{\prime \prime N}, 04^{\circ} 03^{\prime} 13^{\prime \prime W}$ \\
\hline & Ivory Coast: Biaka & $05^{\circ} 28^{\prime} \mathrm{N}, 03^{\circ} 11^{\prime} \mathrm{W}$ \\
\hline & Mali: Tienfala & $12^{\circ} 43^{\prime} \mathrm{N}, 07^{\circ} 44^{\prime} \mathrm{W}$ \\
\hline \multirow[t]{4}{*}{ L. vinosus } & Ivory Coast: Akakro & $05^{\circ} 28^{\prime} 36^{\prime \prime} \mathrm{N}, 03^{\circ} 08^{\prime} 25^{\prime \prime} \mathrm{W}$ \\
\hline & Ivory Coast: Anoblékro & $05^{\circ} 29^{\prime} 44^{\prime \prime N}, 03^{\circ} 22^{\prime} 15^{\prime \prime W}$ \\
\hline & Ivory Coast: Banco & $05^{\circ} 23^{\prime} 17^{\prime \prime N}, 04^{\circ} 03^{\prime} 13^{\prime \prime W}$ \\
\hline & Ivory Coast: Pont Soumié & $05^{\circ} 24^{\prime} 53^{\prime \prime N}, 03^{\circ} 16^{\prime} 56^{\prime \prime W}$ \\
\hline
\end{tabular}

The dissection of nymphs was done in Cellosolve (2-Ethoxyethanol) with subsequent mounting on slides with Euparal liquid, using an Olympus SZX7 stereomicroscope. 
The DNA of some specimens was extracted using non-destructive methods allowing subsequent morphological analysis (see Vuataz et al. 2011 for details). We amplified a $658 \mathrm{bp}$ fragment of the mitochondrial gene cytochrome oxidase subunit 1 (COI) using the primers LCO 1490 and HCO 2198 (Folmer et al. 1994, see Kaltenbach and Gattolliat 2020a for details). Sequencing was done with Sanger's method (Sanger et al. 1977).

Drawings were made using an Olympus BX43 microscope. To facilitate the determination of the new species and the comparison of important structures with other species, we partly used a combination of dorsal and ventral aspects in one drawing (see Kaltenbach et al. 2020: fig. 1).

Photographs of nymphs were taken using a Canon EOS 6D camera and the Visionary Digital Passport imaging system (http://www.duninc.com) and processed with Adobe Photoshop Lightroom (http://www.adobe.com) and Helicon Focus version 5.3 (http://www.heliconsoft.com). Photographs were subsequently enhanced with Adobe Photoshop Elements 13.

Approximate GPS coordinates to the older sample locations (1984-1988) were attributed using Google Earth (https://www.google.com/earth/download/ge/) and Elouard et al. 1990: fig. 2. Distribution maps were generated with SimpleMappr (https:// simplemappr.net, Shorthouse 2010). The coordinates of the sample locations are given in Table 1. The dichotomous key was elaborated with the support of DKey version 1.3.0 (http://drawwing.org/dkey, Tofilski 2018).

The terminology follows Hubbard (1995) and Kluge (2004). The form of the description follows the one used for other recent descriptions of Labiobaetis, as in Kaltenbach et al. 2020.

Abbreviations:

NHM The Natural History Museum (London, Great Britain);

MZL Musée de Zoologie Lausanne (Switzerland).

\section{Results}

\section{List of Labiobaetis species from West Africa}

1. L. boussoulius (Gillies, 1993)

2. L. ediai sp. nov.

3. L. elouardi (Gillies, 1993)

4. L. gambiae (Gillies, 1993)

5. L. glaucus (Agnew, 1961), new for West Africa

6. L. latus (Agnew, 1961), new for West Africa

7. L. piscis Lugo-Ortiz \& McCafferty, 1997

8. L. vinosus (Barnard, 1932), new for West Africa 


\section{Labiobaetis boussoulius (Gillies, 1993)}

\section{Labiobaetis boussoulius: Gillies 1993: figs 4-12 (Baetis boussoulius)}

Differential diagnoses. Nymph. Following combination of characters: A) scape without distolateral process; B) labial palp segment II with broad, thumb-like distomedial protuberance; C) maxillary palp segment II with strongly developed excavation at inner distolateral margin, segment II 1.8-1.9× length of segment I (Fig. 2a); D) fore femur mostly rather slender, length 3.1-4.1× maximum width; dorsal margin with 9-12 spine-like setae; femoral patch well developed (Fig. 3a); E) hind protoptera well developed; F) seven pairs of gills.

Material examined. Holotype. Guinea - Exuviae and male imago; Milo River, Boussoulé; 13.02.1986; leg. M.T. Gillies and J.-M. Elouard; on slides; NHM10017042, NHM10017043; NHM. Other material. GuINEA • 4 nymphs; same data as holotype; on slides; NHM10017044, NHM10017045, NHM10017046, NHM10017047; NHM $\bullet 7$ nymphs, 3 imagos; Milo River, Boussoulé; 22.12.1984; 2 nymphs on slides; GBIFCH00592438, GBIFCH00592763; 5 nymphs, 3 imagos in alcohol; GBIFCH00515625; MZL.

Distribution. Guinea (Fig. 4a).

\section{Labiobaetis ediai sp. nov.}

\section{http://zoobank.org/C705A78B-25AF-4AB8-9E00-CE6D6161C889}

Figures $4 \mathrm{~b}, 5-7$

Differential diagnosis. Nymph. Following combination of characters: A) scape without distolateral process; B) labial palp segment II with rather narrow, thumblike distomedial protuberance; segment III slightly pentagonal; C) maxillary palp segment II with slight excavation at inner distolateral margin; D) fore femur rather broad, length ca. 3× maximum width; dorsal margin with 7-9 curved, spine-like setae; femoral patch absent; E) hind protoptera absent; F) six pairs of gills; G) paraproct slightly expanded, with 35-44 marginal spines.

Description. Nymph (Figs 5-7). Body length 3.3-4.0 mm. Cerci: slightly shorter than body length. Paracercus: ca. $1 / 2$ of cerci length. Antenna: approx. $3 \times$ as long as head length.

Colouration (Fig. 5). Head, thorax and abdomen dorsally and ventrally brown. Legs light brown, caudalii light brown.

Antenna (Fig. 6f) with scape and pedicel subcylindrical, without distolateral process at scape.

Labrum (Fig. 7a). Subrectangular, length $0.6 \times$ maximum width. Distal margin with medial emargination and small process. Dorsally with long, fine, simple setae scattered over surface; submarginal arc of setae composed of ca. 13 long, feathered 


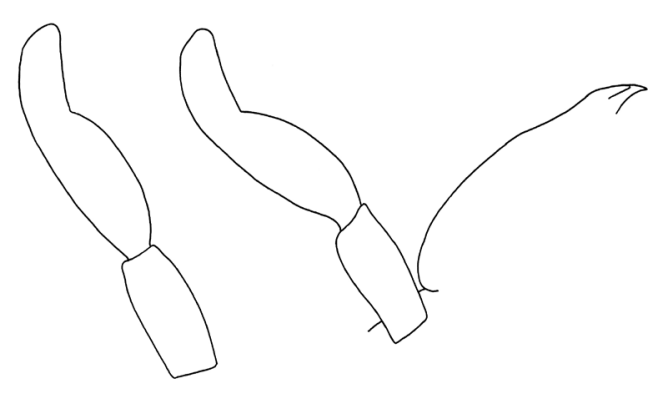

a
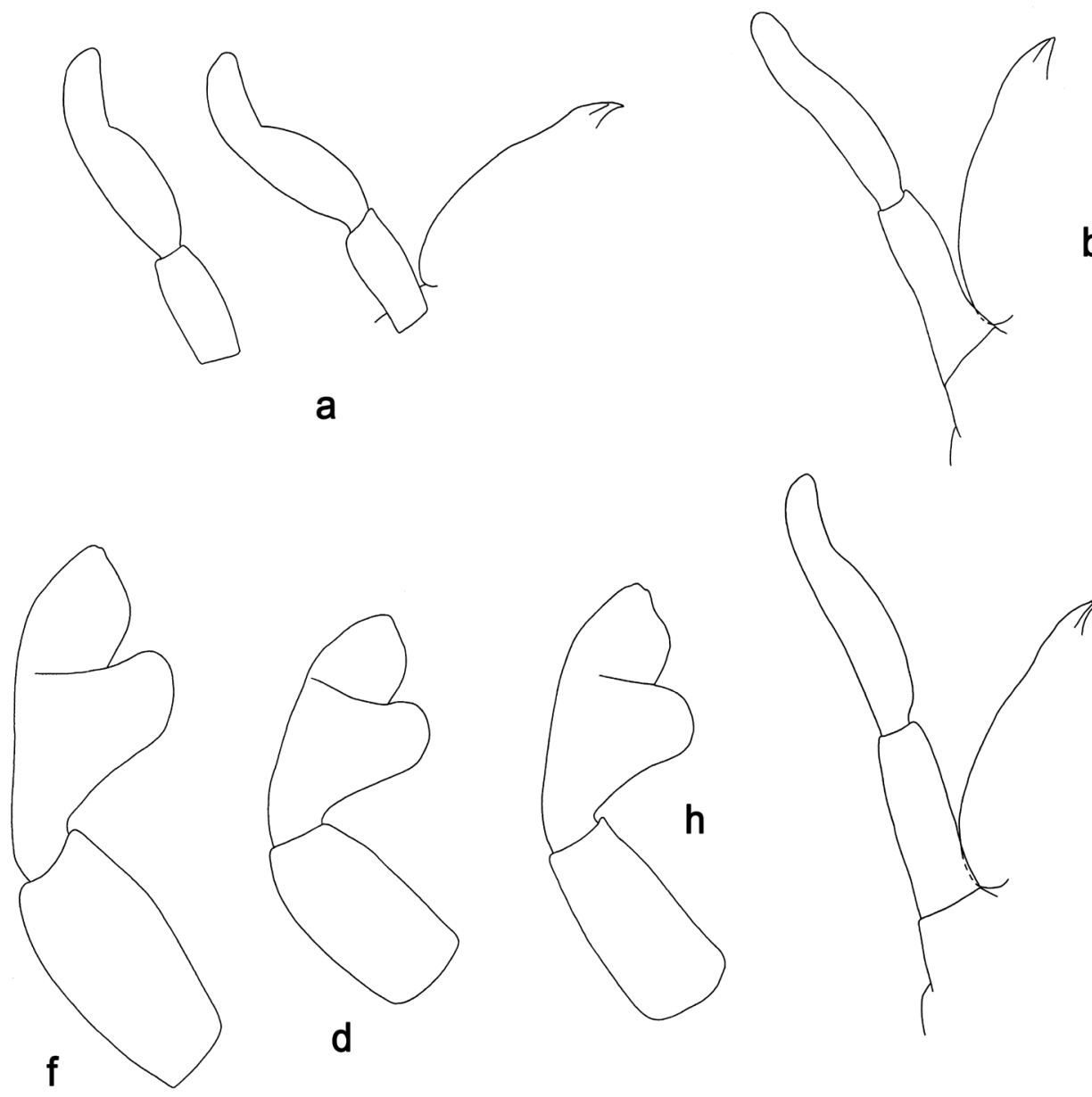

b
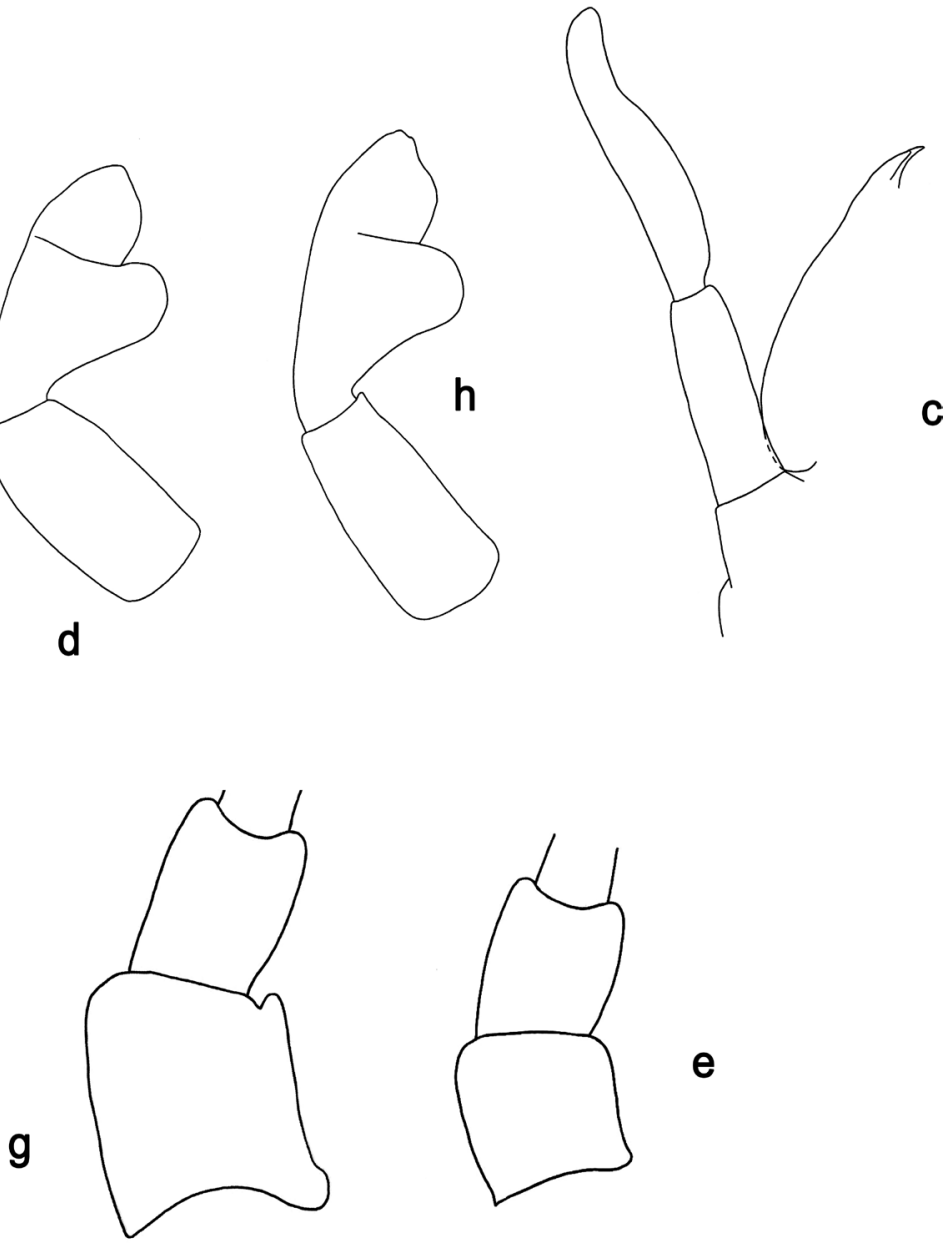

Figure 2. Nymph morphology a Labiobaetis boussoulius, maxillary palps b-e Labiobaetis glaucus $\mathbf{b}, \mathbf{c}$ maxillary palps $\mathbf{d}$ labial palp $\mathbf{e}$ base of antenna $\mathbf{f}, \mathbf{g}$ Labiobaetis latus $\mathbf{f}$ labial palp $\mathbf{g}$ base of antenna h Labiobaetis vinosus, labial palp. Scale bar: $0.1 \mathrm{~mm}$. 

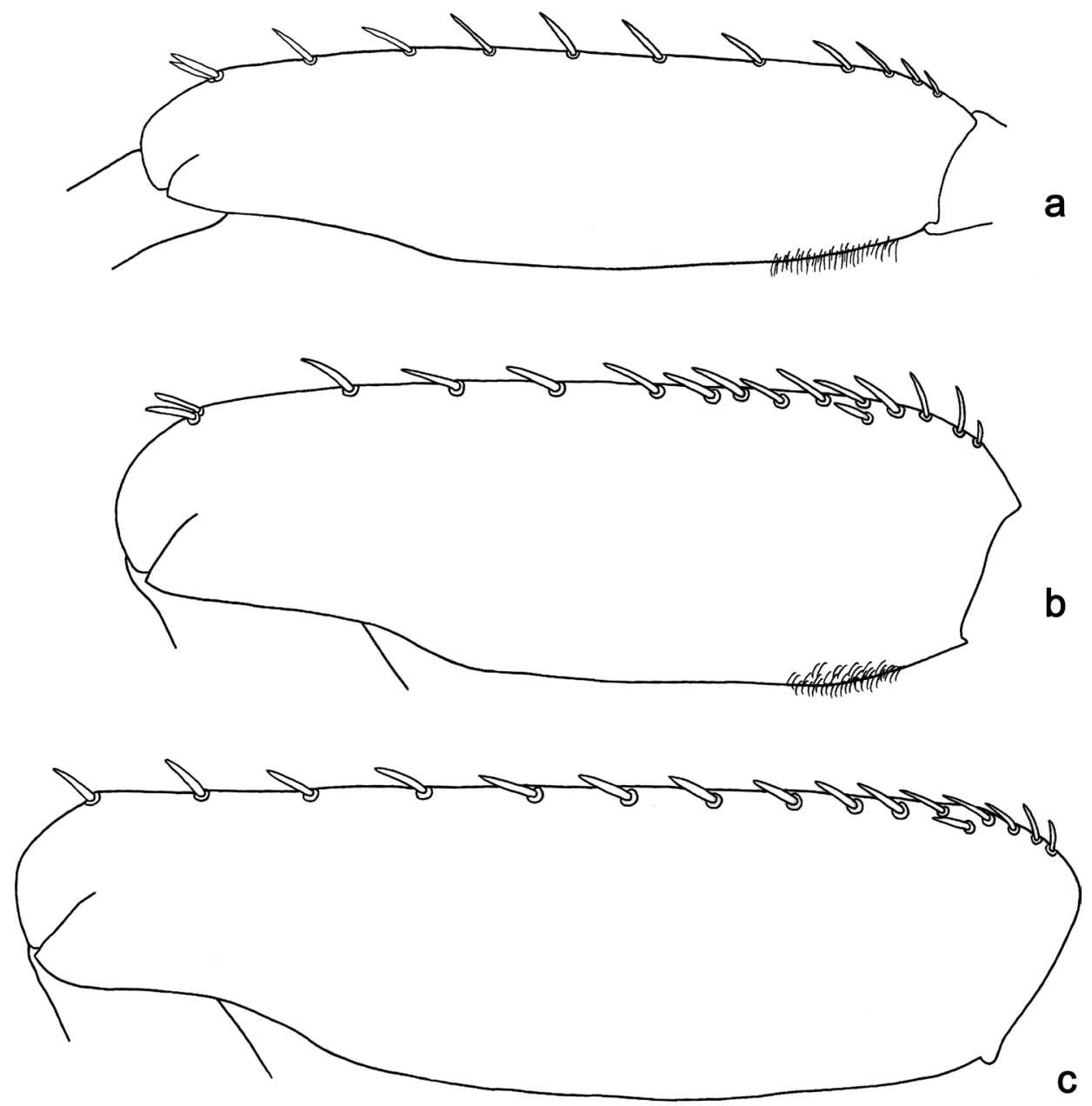

Figure 3. Nymph morphology, fore femur a Labiobaetis boussoulius b Labiobaetis glaucus c Labiobaetis latus. Scale bar: $0.1 \mathrm{~mm}$.

setae. Ventrally with marginal row of setae composed of lateral and anterolateral long, feathered setae and medial long, bifid, pectinate setae; ventral surface with ca. four short, spine-like setae near lateral and anterolateral margin.

Right mandible (Fig. 7b, c). Incisor and kinetodontium fused. Incisor with five denticles; kinetodontium with three denticles, inner margin of innermost denticle with row of thin setae. Prostheca robust, apically denticulate. Margin between prostheca and mola slightly convex, with minute denticles. Tuft of setae at apex of mola present. 

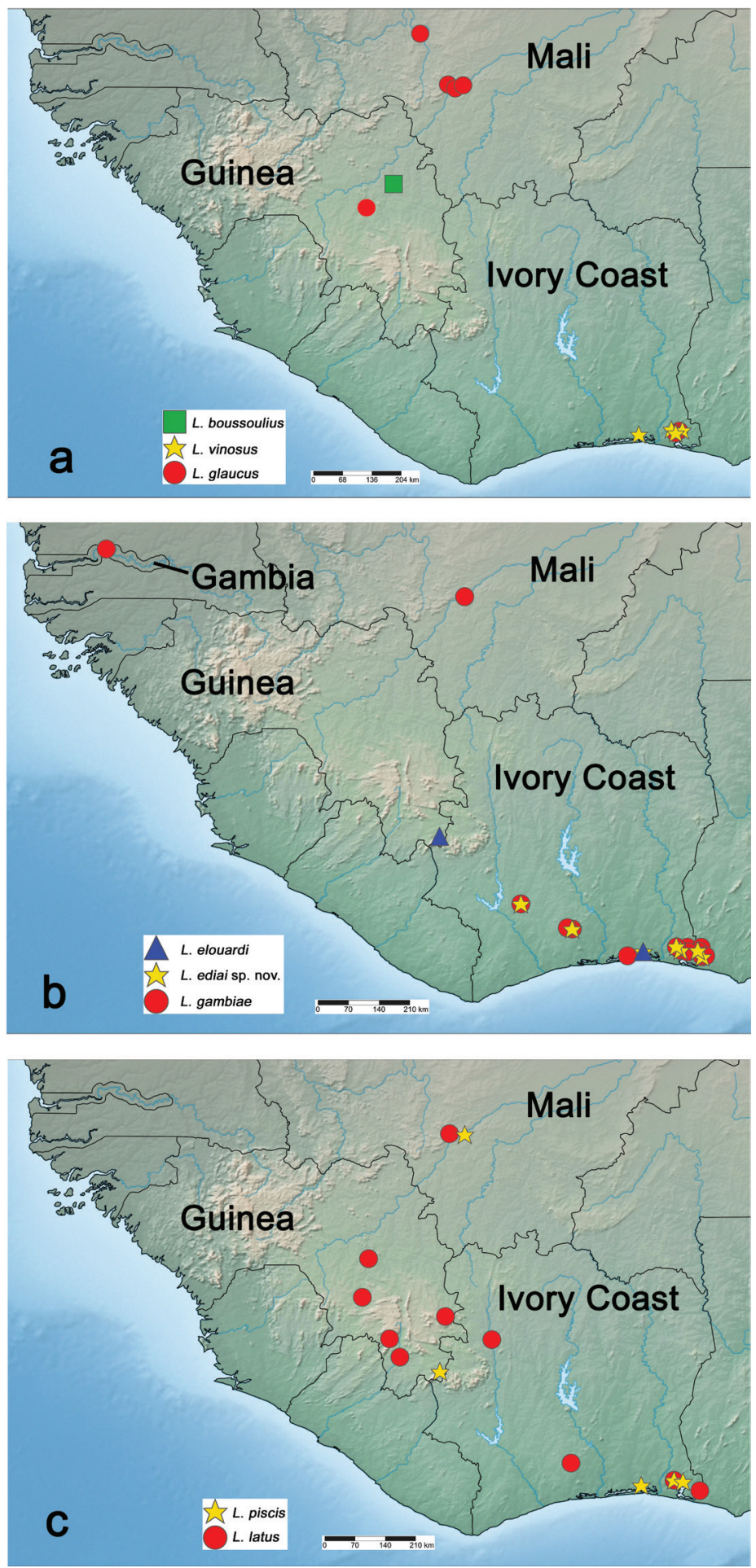

Figure 4. Distribution of Labiobaetis in West Africa. 


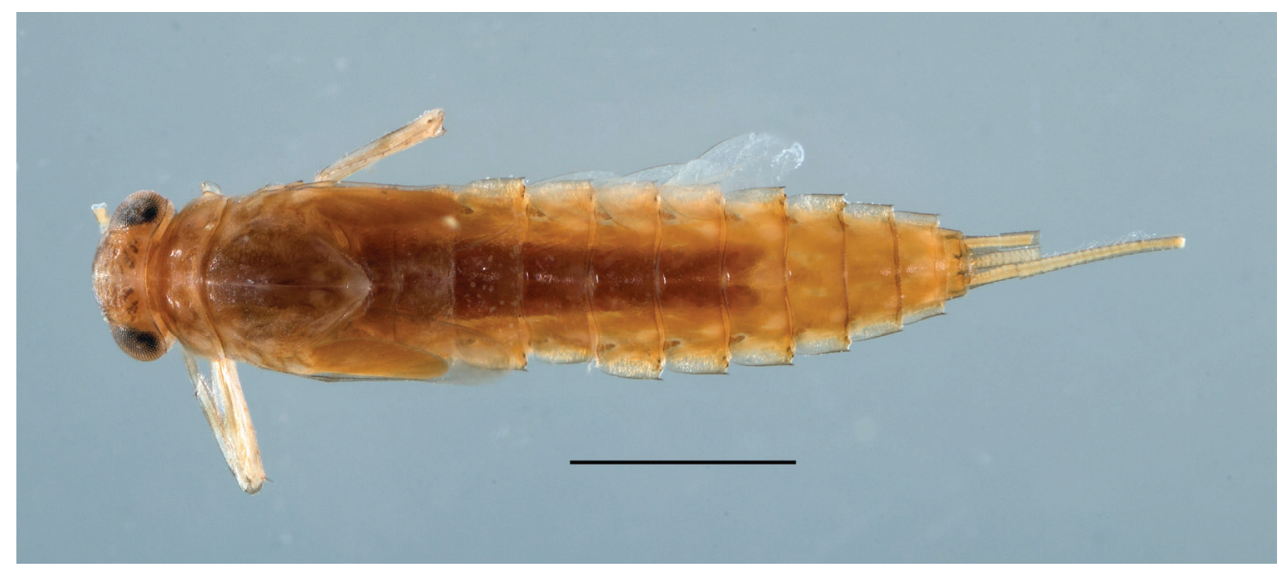

Figure 5. Labiobaetis ediai sp. nov., nymph, habitus. Scale bar: $1 \mathrm{~mm}$.

Left mandible (Fig. 7d, e). Incisor and kinetodontium fused. Incisor with four denticles; kinetodontium with three denticles. Prostheca robust, apically with small denticles and comb-shaped structure. Margin between prostheca and mola almost straight, with minute denticles towards subtriangular process. Subtriangular process long and slender, above level of area between prostheca and mola. Denticles of mola apically constricted. Tuft of setae at apex of mola absent.

Both mandibles with lateral margins almost straight. Basal half with fine, simple setae scattered over dorsal surface.

Hypopharynx and superlinguae (Fig. 7f). Lingua slightly longer than superlinguae. Lingua longer than broad; medial tuft of stout setae well developed; distal half laterally slightly expanded. Superlinguae distally straight; lateral margins rounded; fine, long, simple setae along distal margin.

Maxilla (Fig. 7g). Galea-lacinia ventrally with two simple, apical setae under canines. Inner dorsal row of setae with three denti-setae, distal denti-seta tooth-like, middle and proximal denti-setae slender, bifid and pectinate. Medially with one pectinate, spine-like seta and three or four simple setae. Maxillary palp longer than length of galea-lacinia; 2-segmented; palp segment II $1.5 \times$ length of segment I; setae on maxillary palp fine, simple, scattered over surface of segments I and II; apex of last segment rounded, with slight excavation at inner distolateral margin.

Labium (Fig. 7h). Glossa basally broad, narrowing towards apex; shorter than paraglossa; inner margin with four or five spine-like setae, distalmost seta much longer than other setae; apex with two long and one medium, robust, pectinate setae; outer margin with four or five spine-like setae increasing in length distally; ventral surface with fine, simple, scattered setae. Paraglossa sub-rectangular, curved inwards; apex rounded; with three rows of long, robust, distally pectinate setae in apical area and one or two short, simple setae in anteromedial area; dorsally with row of three long, spine-like, simple setae near inner margin. Labial palp with segment I $0.7 \times$ length of segments II and III combined. Segment I ventrally with short, fine, simple setae. Segment II with rather narrow, 


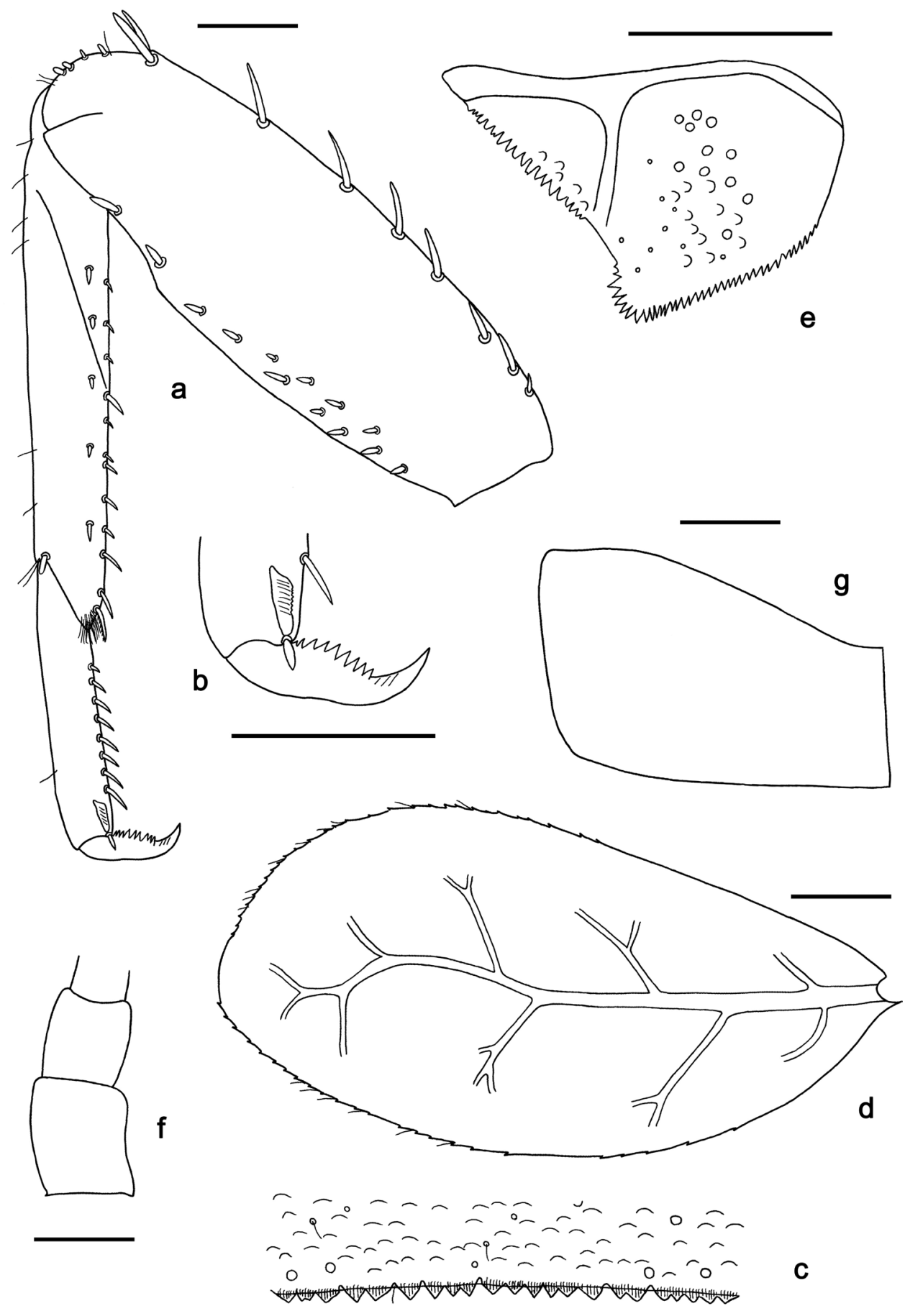

Figure 6. Labiobaetis ediai sp. nov., nymph morphology a foreleg b fore claw $\mathbf{c}$ tergum IV $\mathbf{d}$ gill IV e paraproct $\mathbf{f}$ base of antenna $\mathbf{g}$ metanotum (left side), without hind protopteron (mature nymph). Scale bars: $0.1 \mathrm{~mm}$. 


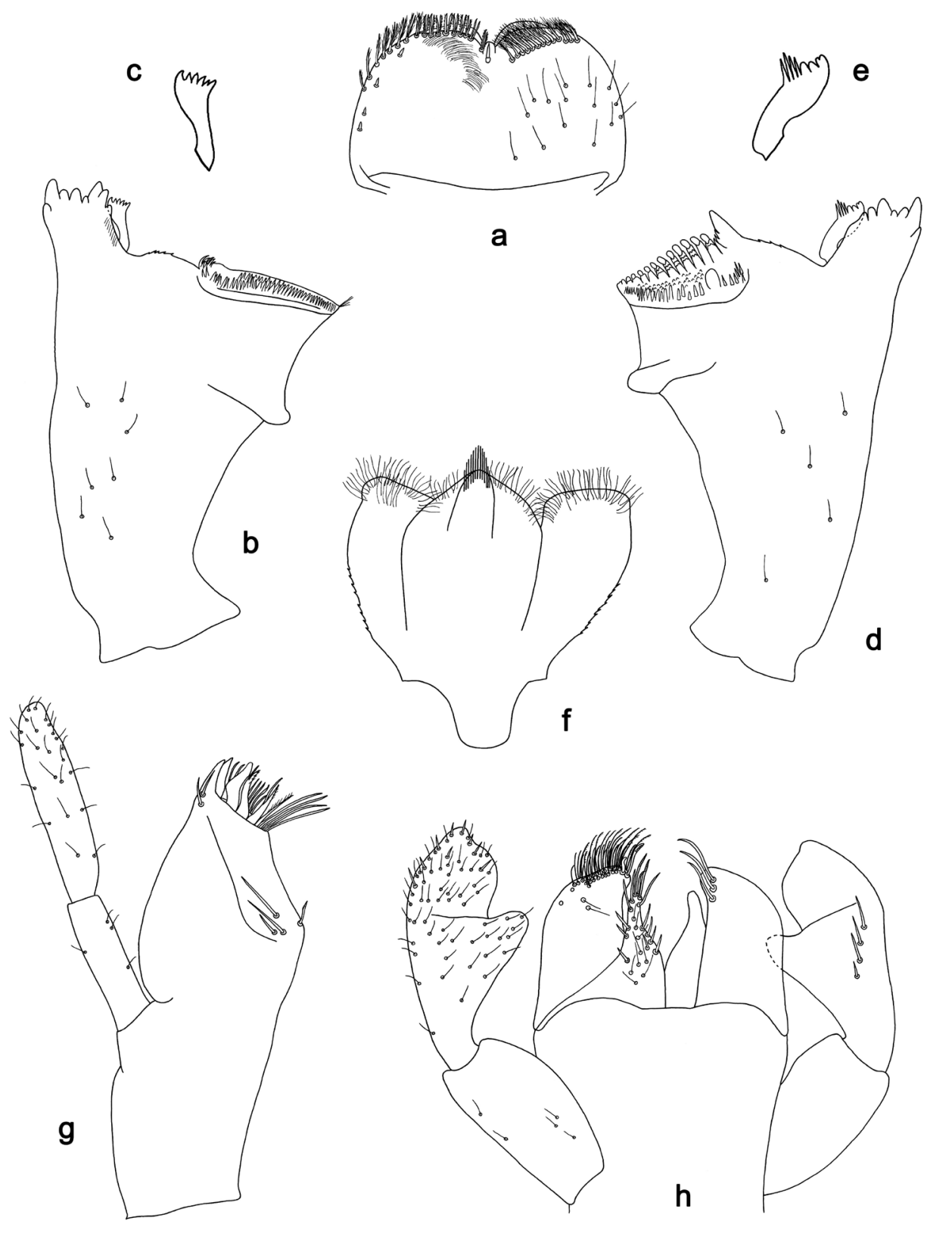

Figure 7. Labiobaetis ediai sp. nov., nymph morphology a labrum $\mathbf{b}$ right mandible $\mathbf{c}$ right prostheca $\mathbf{d}$ left mandible $\mathbf{e}$ left prostheca $\mathbf{f}$ hypopharynx and superlinguae $\mathbf{g}$ maxilla $\mathbf{h}$ labium. Scale bar: $0.1 \mathrm{~mm}$.

thumb-like distomedial protuberance; distomedial protuberance $0.5 \times$ width of base of segment III; ventral surface with short, fine, simple setae; dorsally with four spine-like setae near outer margin. Segment III slightly pentagonal; apex slightly pointed; length $1.1 \times$ width; ventrally covered with short, spine-like, simple setae and short, fine, simple setae. 
Hind protoptera (Fig. 6g) absent.

Foreleg (Fig. 6a, b). Ratio of foreleg segments 1.2:1.0:0.6:0.2. Femur. Length ca. $3 \times$ maximum width. Dorsal margin with 7-9 curved, spine-like setae; length of setae $0.29 \times$ maximum width of femur. Apex rounded, with pair of spine-like setae and some short, stout setae. Stout, lanceolate setae scattered along ventral margin; femoral patch absent. Tibia. Dorsal margin with row of scarce, fine simple setae. Ventral margin with row of short to medium, curved, spine-like setae, distad of patellotibial suture one longer, curved, spine-like seta, on apex, some longer setae and tuft of fine, simple setae. Anterior surface scattered with short, stout, lanceolate setae. Patellotibial suture present on basal half area. Tarsus. Dorsal margin almost bare. Ventral margin with row of curved, spine-like setae. Claw with one row of nine or ten denticles; distally pointed; with ca. three stripes; subapical setae absent.

Terga (Fig. 6c). Surface with irregular rows of U-shaped scale bases and scattered fine, simple setae and micropores. Posterior margin of tergum IV with triangular spines, wider than long.

Gills (Fig. 6d). Present on segments II-VII. Margin with small denticles intercalating fine simple setae. Tracheae extending from main trunk to inner and outer margins. Gill IV as long as length of segments V, VI and half VII combined; gill VII as long as length of segments VIII, IX and half X combined.

Paraproct (Fig. 6e). Distally slightly expanded, with 35-44 marginal spines. Surface scattered with U-shaped scale bases and micropores. Cercotractor with small, marginal spines.

Etymology. Dedicated to the collector of the specimens, Dr. Edia Oi Edia (Université Nangui Abrogoua, Abidjan, Ivory Coast), in recognition of his contribution to the knowledge of aquatic insects from the Ivory Coast.

Biological aspects. The specimens were collected at altitudes between sea level and $200 \mathrm{~m}$, mostly together with one or several other West African species (L. elouardi, L. gambiae, L. glaucus, L. latus, L. piscis and L. vinosus). The characteristics and environmental conditions of some of the sampling sites are described in Edia et al. 2015: table $2($ Anoblékro $=$ S1, Pont Ehania $=$ Eh2, Pont Soumié $=$ S2): water temperature ca. $25^{\circ} \mathrm{C}, \mathrm{pH} 6.8-7.1$ and bottom substrata consisting of $0-25 \%$ rocks, $10-35 \%$ gravel, $40-45 \%$ sand and $20-35 \%$ clay/mud.

Distribution. Ivory Coast (Fig. 4b).

Type-material. Holotype. IvORY COAST $\bullet$ nymph; Loc. Pont Ehania, Riv. Ehania; $05^{\circ} 16^{\prime} 42^{\prime \prime N}, 02^{\circ} 50^{\prime} 01^{\prime \prime W}$; 14.06.2008; leg. J.-L. Gattolliat and E.O. Edia; on slide; GenBank MH070294; GBIFCH00465136; MZL. Paratypes. Ivory CoAst - 21 nymphs; same data as holotype; 18 in alcohol; GBIFCH00515550, GBIFCH00515551, GBIFCH00515623; 3 on slides; GenBank MH070295; GBIFCH00465137, GBIFCH00592376, GBIFCH00592408; MZL • 1 nymph; Riv. Soumié, Loc. Anoblékro; 05²9'44"N, 03²2'15"W; 01.09.2003; leg. E.O. Edia; on slide; GBIFCH00592379; MZL • 9 nymphs; Grobiakoko; 0551'18"N, 05³1'00"W; 29.10.2006; leg. E.O. Edia; 7 in alcohol; GBIFCH00515541, GBIFCH00515624; 2 on slides; GBIFCH00592401, GBIFCH00592449; MZL - 15 nymphs; Goré; $06^{\circ} 22^{\prime} 28^{\prime \prime} \mathrm{N}, 06^{\circ} 34^{\prime} 27^{\prime \prime W}$; 26.10.2006; leg. E.O. Edia; 14 in alcohol; GBIF- 
CH00515545; 1 on slide; GBIFCH00592738; MZL • 2 nymphs; Loc. Réserve Naturelle Banco, Abidjan, station aval; 18.06.2008; leg. J.-L. Gattolliat and E.O. Edia; on slides; GBIFCH00465139, GBIFCH00465140; MZL - 5 nymphs; Riv. Ehania, Pont Ehania; $05^{\circ} 16^{\prime} 42^{\prime \prime} \mathrm{N}, 02^{\circ} 50^{\prime} 02^{\prime \prime} \mathrm{W} ; 12.03 .2005$; leg. E.O. Edia; 4 in alcohol; GBIFCH00515605; 1 on slide; GBIFCH00592457; MZL. Other material. IvoRY

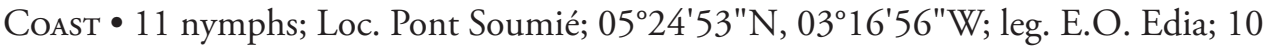
in alcohol; GBIFCH00515612; 1 on slide; GBIFCH00592733; MZL • 14 nymphs; Riv. Ehania, Loc. Affiénou; 05²4'39"N, 0255'43"W; 04.08.2004; leg. E.O. Edia; 13 in alcohol; GBIFCH00515613; 1 on slide; GBIFCH00592734; MZL.

\section{Labiobaetis elouardi (Gillies, 1993)}

Labiobaetis elouardi: Gillies 1993: figs 17-27 (Baetis elouardi)

Differential diagnosis. Nymph. Following combination of characters: A) scape with well-developed distolateral process (Fig. 8e); B) labrum rectangular, dorsally with a submarginal arc of peculiar setae (Fig. 8a, h-j); C) mandibles with incisor and kinetodontium apically cleft (Fig. 8b, c); D) glossae much shorter than paraglossae (Fig. 8d); labial palp segment II with broad thumb-like protuberance; E) hind protoptera absent; F) six pairs of gills; G) paraproct with 2-3 stout, marginal spines (Fig. 8f, g).

Examined material. Ivory CoAst - 28 nymphs; Abidjan, Banco, Réserve Naturelle; $05^{\circ} 23^{\prime} 17^{\prime \prime} \mathrm{N}, 04^{\circ} 03^{\prime} 13^{\prime \prime W}$; 17.07.2007; leg. E.O. Edia; 24 in alcohol; GBIFCH00515540, GBIFCH00515547; 4 on slides; GBIFCH00592400, GBIFCH00592402, GBIFCH00592405, GBIFCH00592406 • 7 nymphs; Abidjan, Banco, Réserve Naturelle; 05²3'17"N, 0403'13"W;18.06.2008; leg. J.-L. Gattolliat and E.O. Edia; 6 in alcohol; GBIFCH00515607, GBIFCH00515608; 1 on slide; GBIFCH00592459. Guinea 3 nymphs; Bas. Cavally, Riv. Cavally, Loc. Mt. Nimba (nord-ouest); 01.02.1988; Coll. ORSTOM; leg. J.-M. Elouard; on slides; GBIFCH00592433, GBIFCH00592434, GBIFCH00592435; all material in MZL.

Distribution. Guinea, Ivory Coast (Fig. 4b).

\section{Labiobaetis gambiae (Gillies, 1993)}

Labiobaetis gambiae: Gillies 1993: figs 30-37 (Baetis gambiae); Edia et al. 2015

Differential diagnoses. Nymph. Following combination of characters: A) scape without distolateral process; B) labial palp segment II with narrow, thumb-like protuberance, segment III enlarged, slightly pentagonal (Fig. 9b); C) maxillary palp segment II with slight excavation at inner, distolateral margin; D) fore femur rather slender, length ca. $4 \times$ maximum width; dorsal margin with ca. eight curved, spine-like setae; femoral patch absent; E) hind protoptera small (Fig. 9a); F) seven pairs of gills. 

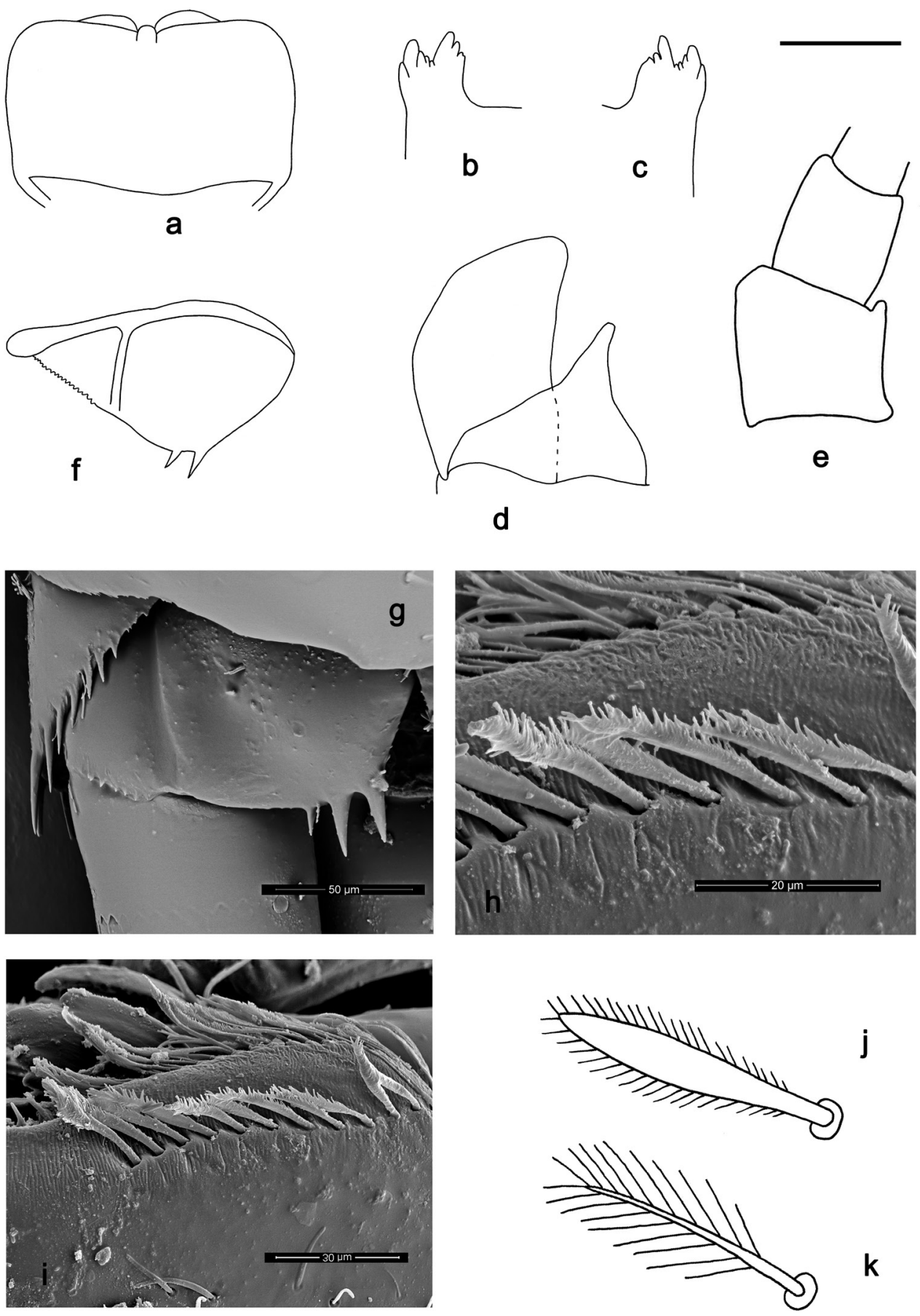

$\mathbf{k}$

Figure 8. a-i Labiobaetis elouardi, nymph morphology a labrum b incisor and kinetodontium of right mandible $\mathbf{c}$ incisor and kinetodontium of left mandible $\mathbf{d}$ glossa and paraglossa $\mathbf{e}$ base of antenna f, $\mathbf{g}$ paraproct. SEM photos, Labrum, dorsal surface, right side, submarginal arc of setae (h section of figure $\mathbf{i}) \mathbf{j}$ seta of submarginal arc on dorsal surface of labrum $\mathbf{k}$ usual type of feathered seta of submarginal arc on dorsal surface of labrum. Scale bar: $0.1 \mathrm{~mm}(\mathbf{h}, \mathbf{i})$. 

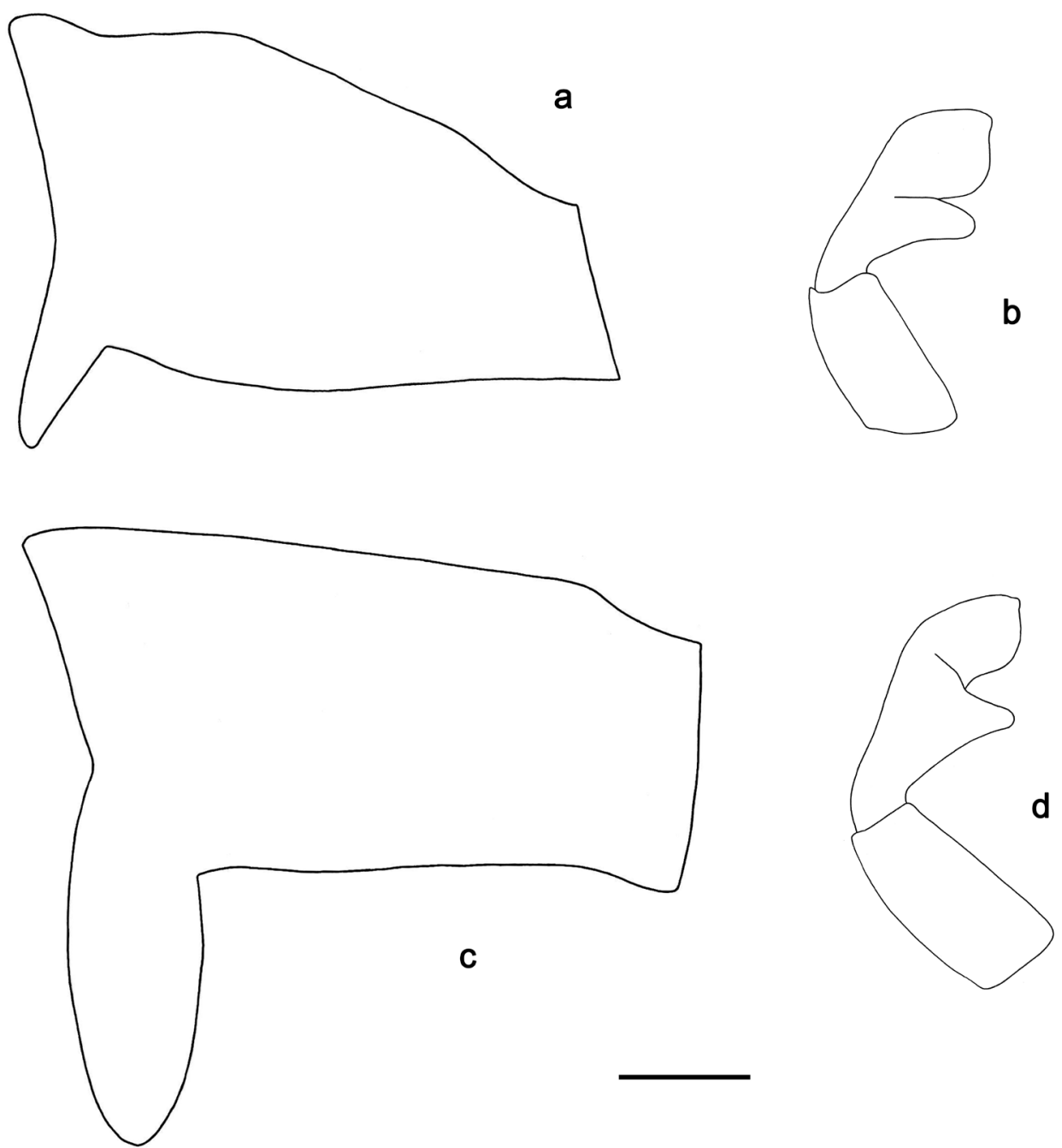

Figure 9. Nymph morphology a, b Labiobaetis gambiae $\mathbf{a}$ metanotum (left side), with small hind protopteron (mature nymph) b labial palp c, d Labiobaetis piscis $\mathbf{c}$ metanotum (left side), with well-developed hind protopteron (mature nymph) d labial palp. Scale bar: $0.1 \mathrm{~mm}$.

Material examined. Gambia • 4 nymphs; River Gambia, Wali Kunda; 01.10.1981; on slides; NHM10017019, NHM10017020, NHM10017022, NHM10017023; NHM • 2 nymphs; River Gambia, Wali Kunda; 07.10.1981; on slides; NHM10017021, NHM10017026; NHM • 1 nymph; River Gambia, Wali Kunda; 10.1986; on slide; NHM10017024; NHM. Ivory CoAst 1 nymph; Riv. Eholié, Akakro; $05^{\circ} 28^{\prime} 36^{\prime \prime N}, 03^{\circ} 08^{\prime} 25^{\prime \prime W}$; 01.10.2003; leg. E.O. Edia; on slide; GBIFCH00592452; MZL • 26 nymphs; Riv. Noé, Loc. M'possa; 05²8'37"N, 0251'30"W; 30.06.2004; leg. E.O. Edia; 1 on slide; GBIFCH00592731; 25 in alcohol; GBIFCH00515610; MZL • 62 nymphs; Riv. Soumié, Loc. Pont Soumié; 
$05^{\circ} 24^{\prime} 53^{\prime \prime N}$, 03 $16^{\prime} 56^{\prime \prime W} ; 14.06 .2008$; leg. J.-L. Gattolliat and E.O. Edia; 1 on slide; GBIFCH00592732; 61 in alcohol; GBIFCH00515611; MZL • 13 nymphs; Grobiakoko; 0551'18"N, 05³1'00"W; 29.10.2006; leg. E.O. Edia; 1 on slide; GBIFCH00592736; 12 in alcohol; GBIFCH00515616; MZL • 15 nymphs; Niambré; $05^{\circ} 52^{\prime} 46 " \mathrm{~N}, 05^{\circ} 36^{\prime} 55^{\prime \prime W}$; 19.07.2007; leg. E.O. Edia; in alcohol; GBIFCH00515544; MZL • 16 nymphs; Boubo; 0518'08"N, 04²2'37"W; 19.07.2007; leg. E.O. Edia; 1 on slide; GBIFCH00592737; 15 in alcohol; GBIFCH00515543; MZL • 1 nymph; Goré; 06 $22^{\prime} 28^{\prime \prime N}, 06^{\circ} 34^{\prime} 27^{\prime \prime W} ; 26.10 .2006$; leg. E.O. Edia; in alcohol; GBIFCH00515618; MZL. MALI 1 nymph; River Niger, 30 km downstream Bamako, Tyenfala (= Tienfala); 05.02.1986; on slide; NHM10017025; NHM.

Distribution. Gambia, Ivory Coast, Mali (Fig. 4b).

\section{Labiobaetis glaucus (Agnew, 1961)}

Labiobaetis glaucus: Agnew 1961 (Baetis glaucus); Lugo-Ortiz and McCafferty 1997: figs 27-38, 39-50 (Labiobaetis masai, L. nadineae; formal synonyms, Lugo-Ortiz et al. 2000); Lugo-Ortiz et al. 2000: figs 1-11 (Pseudocloeon glaucum); Gattolliat et al. 2018: figs 34-44, 47

Differential diagnosis. Nymph. Following combination of characters: A) scape without distolateral process (Fig. 2e); B) labial palp segment II with broad thumb-like protuberance (Fig. 2f); C) maxillary palp segment II with excavation at inner distolateral margin, segment II ca. 1.5 $\times$ length of segment I (Fig. 2b, c); D) fore femur mostly rather broad, length 2.7-3.2× maximum width; dorsal margin with 13-18 curved, spine-like setae and often basally some additional setae near margin; femoral patch well developed (Fig. 3b); E) hind protoptera well developed; F) seven pairs of gills; G) paraproct with 5-13 stout, marginal spines.

Examined material. Guinea - 1 nymph; Guinea; Bas. Niger, Riv. Niandan, Loc. Sassambaya; 23.12.1984; Coll. ORSTOM; leg. J-M Elouard; on slide; GBIFCH00592422; MZL. Ivory Coast 17 nymphs; Loc. Aboisso, Riv. Bia; 05²8'04"N, 0312'26"W; 14.06.2008; leg. J.-L. Gattolliat and E.O. Edia; 1 on slide; GBIFCH00592407; 16 in alcohol; GBIFCH00515549; MZL • 1 nymph; Pont Soumié; $05^{\circ} 24^{\prime} 53^{\prime \prime N}, 03^{\circ} 16^{\prime} 56^{\prime \prime W}$; 04.04.2005; leg. E.O. Edia; on slide; GBIFCH00592451; MZL. Malı 47 nymphs; Bas. Niger, Riv. Niger, Loc. Tienfala (= Tyenfala); 21.03.1985; Coll. ORSTOM; leg. J.-M. Elouard; 44 in alcohol; GBIFCH00515532; 3 on slides; GBIFCH00592396, GBIFCH00592426, GBIFCH00592427; MZL • 9 nymphs; Bas. Sénégal, Riv. Baoule, Loc. Kati-Kita (route); 22.11.1984; Coll. ORSTOM, leg. J.M. Elouard; 8 in alcohol; GBIFCH00515533; 1 on slide; GBIFCH00592397; MZL - 26 nymphs; Bas. Sénégal, Riv. Baoule, Loc. Missira; 09.10.1984; Coll. ORSTOM, leg. J.-M. Elouard; in alcohol; GBIFCH00515534; MZL • 10 nymphs; Riv. Niger, Sotuba; 16.01.1985; leg. J.-M. Elouard; 9 in alcohol; GBIFCH00515570; 1 on slide; GBIFCH00592416; MZL. 
Distribution. Guinea, Ivory Coast, Mali (Fig. 4a), Ethiopia (Kaltenbach and Gattolliat 2021), potentially Iran (Tahmasebi et al. 2020), Angola (Barber-James and Ferreira 2019), Saudi Arabia, Mayotte (Gattolliat et al. 2018), South Africa, Lesotho, Namibia, Kenya (Lugo-Ortiz et al. 2000), Zimbabwe (Harrison and Hynes 1988).

\section{Labiobaetis latus (Agnew, 1961)}

Labiobaetis latus: Agnew 1961 (Baetis latus); Lugo-Ortiz and McCafferty 1997: figs 1-13 (Labiobaetis aquacidus; formal synonym, Lugo-Ortiz and de Moor 2000)

Differential diagnosis. Nymph. Following combination of characters: A) scape with well-developed distolateral process (Fig. 2g); C) labial palp segment II with broad thumb-like protuberance (Fig. 2f); D) maxillary palp segment II with excavation at inner distolateral margin; E) fore femur rather broad, length ca. $3 \times$ maximum width; dorsal margin with 13-18 curved, spine-like setae; femoral patch absent (Fig. 3c); F) hind protoptera well developed; G) seven pairs of gills; H) paraproct with 21-29 stout, marginal spines.

Examined material. GUINEA $\bullet 2$ nymphs; Férédougouba, stat. près confluent, Beya et M’bôo (Riv.6); 09.09.1988; leg. J.-M. Elouard; 1 in alcohol; GBIFCH00515501; 1 on slide; GBIFCH00592375; MZL - 5 nymphs; Bas. Loffa, Riv. Loffa, Loc. Loffa (Mission Agnès); 30.01.1988; ORSTOM; leg. J.-M. Elouard; in alcohol; GBIFCH00592420; MZL • 13 nymphs; Bas. Niger, Riv. Niandan, Loc. Sassambaya; 23.12.1984; Coll. ORSTOM; leg. J.-M. Elouard; 10 in alcohol; GBIFCH00515535, GBIFCH00515569, GBIFCH00515536; 2 on slides; GBIFCH00592421, GBIFCH00592398; MZL • 1 nymph; Riv. Niandan, Loc. Sassambaya; 19.04.1986; leg. J.-M. Elouard; on slide; GBIFCH00592414; MZL; 2 nymphs; Bas. Niger, Riv. Niandan, Loc. Kissidougou-Kankan (route); 26.10.1984; Coll. ORSTOM; leg. J.M. Elouard; in alcohol; GBIFCH00592418; MZL • 1 nymph; Haute Diani, près Diomandau; 08 $55^{\prime} 00^{\prime \prime N}, 08^{\circ} 07^{\prime} 60^{\prime \prime W}$; 08.03.1988; leg. J.-M. Elouard; in alcohol; GBIFCH00515537; MZL • 1 nymph; Bas. St. Paul (= Diani), Riv. St. Paul, Loc. N'Zébéla; 31.01.1988; Coll. ORSTOM; leg. J.-M. Elouard; in alcohol; GBIFCH00592419; MZL • 1 nymph; Kon Launtau; 28.I.1989; leg. J.-M. Elouard; in alcohol; GBIFCH00515538; MZL. Ivory COAST • 3 nymphs; Lagboayo; 18.07.2007; leg. E.O. Edia; 2 in alcohol; GBIFCH00515539; 1 on slide; GBIFCH00592399; MZL• 2 nymphs; Lagboayo; 27.10.2006; leg. E.O. Edia; in alcohol; GBIFCH00515546; MZL • 23 nymphs; Loc. Pont Ehania, Riv. Ehania; 05¹6'42"N, 0250'01"W; 14.06.2008; leg. Gattolliat and E.O. Edia; in alcohol; GBIFCH00515601; MZL • 2 nymphs; Grobiakoko; 05 51'18"N, 05³1'00"W; 29.10.2006; leg. E.O. Edia; 1 in alcohol; GBIFCH00515617; 1 on slide; GBIFCH00592450; MZL • 3 nymphs; 
Grobiakoko; 0551'18"N, 05³1'00"W; 19.07.2007; leg. E.O. Edia; 2 in alcohol; GBIFCH00515542; 1 on slide; GBIFCH00592739; MZL • 11 nymphs; Riv. Soumié, Loc. Anoblékro; $05^{\circ} 29^{\prime} 44^{\prime \prime N}$, 03²2'15"W; 06.03.2005; leg. E.O. Edia; 10 in alcohol; GBIFCH00515614; 1 on slide; GBIFCH00592735; MZL. MaLI 1 nymph; Bas. Sénégal, Riv. Baoule, Loc. Kati-Kita (route); 22.11.1984; Coll. ORSTOM, leg. J.-M. Elouard; on slide; GBIFCH00592374; MZL.

Distribution. Guinea, Ivory Coast, Mali (Fig. 4c), Ethiopia (Kaltenbach and Gattolliat 2021), South Africa, Kenya (Lugo-Ortiz and McCafferty 1997).

\section{Labiobaetis piscis Lugo-Ortiz \& McCafferty, 1997}

Labiobaetis piscis: Lugo-Ortiz and McCafferty 1997: figs 51-62

Differential diagnosis. Nymph. Following combination of characters: A) scape without distolateral process; B) labial palp segment II with narrow, thumb-like protuberance; segment III slightly pentagonal (Fig. 9d); D) maxillary palp segment II with slight excavation at inner distolateral margin; E) fore femur rather broad, length ca. $3 \times$ maximum width; dorsal margin with 7-10 curved, spine-like setae; femoral patch absent or rudimentary; F) hind protoptera well developed (Fig. 9c); G) seven pairs of gills; H) paraproct with 35-40 marginal spines.

Examined material. GuineA 1 nymph; Bas. Cavally, Riv. Cavally, Loc. Mt. Nimba (nord-ouest); 01.02.1988; Coll. ORSTOM; leg. J.-M. Elouard; on slide; GBIFCH00592395; MZL. Ivory COAST 1 nymph; Abidjan; Banco, Réserve Naturelle; $05^{\circ} 23^{\prime} 17^{\prime \prime} \mathrm{N}, 04^{\circ} 03^{\prime} 13^{\prime \prime W}$; 17.07.2007; leg. E.O. Edia; on slide; GBIFCH00592403; MZL • 7 nymphs; Riv. Soumié, Loc. Anoblékro; 05²9'44"N, 0322'15"W; 01.09.2003; leg. E.O. Edia; 6 in alcohol; GBIFCH00515548; 1 on slide; GBIFCH00592378; MZL • 1 nymph; Riv. Soumié, Loc. Anoblékro; 05²9'44"N, 0322'15"W; 06.03.2005; leg. E.O. Edia; on slide; GBIFCH00592453; MZL • 2 nymphs; Riv. Soumié, Loc. Anoblékro; 05²9'44"N, 03²2'15"W; 01.07.2003; leg. E.O. Edia; on slides; GBIFCH00592454, GBIFCH00592377; MZL • 8 nymphs; Loc. Biaka, Riv. Biaka; $05^{\circ} 28^{\prime} \mathrm{N}, 03^{\circ} 11^{\prime} \mathrm{W} ; 14.06 .2008$; leg. J.-L. Gattolliat and E.O. Edia; 7 in alcohol; GBIFCH00515603; 1 on slide; GBIFCH00592458; MZL. MALI • 11 nymphs; Bas. Niger, Riv. Niger, Loc. Tienfala (= Tyenfala); 21.03.1985; Coll. ORSTOM; leg. J.-M. Elouard; 9 in alcohol; GBIFCH00515528, GBIFCH00515530; 2 on slides; GBIFCH00592394, GBIFCH00592415; MZL • 1 nymph; Bas. Niger, Riv. Niger, Loc. Tienfala (= Tyenfala); 26.06.1985; Coll. ORSTOM; leg. J.-M. Elouard; on slide; GBIFCH00592424; MZL.

Distribution. Guinea, Ivory Coast, Mali (Fig. 4c), Angola (Barber-James and Ferreira 2019), potentially Nigeria (Arimoro and Muller 2010), South Africa (Lugo-Ortiz and McCafferty 1997). 


\section{Labiobaetis vinosus (Barnard, 1932)}

Labiobaetis vinosus: Barnard 1932 (Pseudocloeon vinosum); Kopelke 1980 (Pseudocloeon tenuicrinitum; informal synonym, Kluge 2021); Gillies 1994: figs 16-26 (Baetis spatulatus; formal synonym, Kluge and Novikova 2016); Lugo-Ortiz and McCafferty 1997: figs 75-86; Kluge and Novikova 2016: figs 113, 122-129, 132, 133 (L. tenuicrinitus; informal synonym, Kluge 2021)

Differential diagnosis. Nymph. Following combination of characters: A) scape without distolateral process; B) labial palp segment II with broad, thumb-like protuberance (Fig. 2h); C) maxillary palp segment II with excavation at inner distolateral margin; D) fore femur rather broad, length ca. $3 \times$ maximum width; dorsal margin with 8-18 curved, spine-like setae and basally a partial second row of setae; E) hind protoptera absent or minute; F) six pairs of gills.

Examined material. Ivory COAST - 4 nymphs; Loc. Réserve Naturelle Banco, Abidjan, station aval; $05^{\circ} 23^{\prime} 17^{\prime \prime} \mathrm{N}, 04^{\circ} 03^{\prime} 13^{\prime \prime W}$; 18.06 .2008 ; leg. J.-L. Gattolliat and E.O. Edia; on slides; GBIFCH00592404; GBIFCH00592430, GBIFCH00592431, GBIFCH00592432; MZL • 1 nymph; Loc. Pont Soumié, River Soumié; 05²4'53"N, 0316'56"W; 14.06.2008; leg.J.-L. GattolliatandE.O. Edia; on slide; GBIFCH00592429; MZL • 1 nymph; Riv. Soumié, Loc. Anoblékro; 05²9'44"N, 03²2'15"W; 01.12.2003; leg. E.O. Edia; on slide; GBIFCH00592428; MZL - 42 nymphs; Riv. Eholié, Loc. Akakro; 0528'36"N, 0308'25"W; 03.07.2004; leg. E.O. Edia; 41 in alcohol; GBIFCH00515609, GBIFCH00515606; 1 on slide; GBIFCH00592460; MZL.

Distribution. Ivory Coast (Fig. 4a), Ethiopia (Kaltenbach and Gattolliat 2021), Angola (Barber-James and Ferreira 2019), Uganda (Kluge and Novikova 2016), South Africa (Lugo-Ortiz and McCafferty 1997), Tanzania (Gillies 1994), DR Congo (Kopelke 1980).

\section{Key to the Labiobaetis species of West Africa (nymphs)}

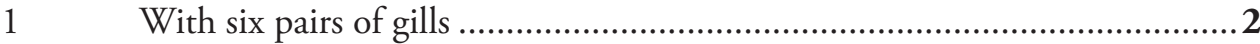

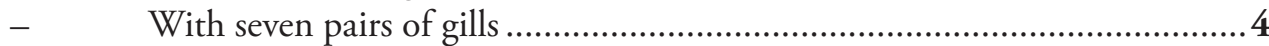

2 With distolateral process at scape; labrum rectangular; mandibles with incisor and kinetodontium apically cleft; glossae much shorter than paraglossae; paraproct with two or three spines (Fig. 8a-g) ........................... L. elouardi

- Without distolateral process at scape; labrum subrectangular; mandibles with incisor and kinetodontium fused; glossae somewhat shorter than paraglossae; paraproct with many spines

3 Labial palp segment II with broad thumb-like, distomedial protuberance (Fig. 2h) L. vinosus

- Labial palp segment II with narrow thumb-like, distomedial protuberance (Fig. 7h) L. ediai sp. nov. 
$4 \quad$ Labial palp segment II narrow thumb-like (Fig. 9b, d) .............................. 5

- $\quad$ Labial palp segment II broad thumb-like (Fig. 2d, f) ...................................6

$5 \quad$ Hind protoptera small (Fig. 9a); labial palp segment III enlarged (Fig. 9b).....

L. gambiae

- $\quad$ Hind protoptera well developed (Fig. 9c); labial palp segment III not enlarged (Fig. 9d) ........................................................................... L. piscis

6 Scape with distolateral process (Fig. 2g); femoral patch at fore femur absent (Fig. 3c)

L. latus

- $\quad$ Scape without distolateral process (Fig. 2e); femoral patch at fore femur well developed (Fig. 3a, b) .7

7 Fore femur length 3.1-4.1× maximal width, dorsally with row of 9-12 spinelike setae (Fig. 3a); maxillary palp segment II with strongly developed, distolateral excavation, segment II 1.8-1.9× length of segment I (Fig. 2a)

L. boussoulius

- $\quad$ Fore femur length 2.7-3.2x maximal width, dorsally with row of 13-18 spine-like setae (Fig. 3b); maxillary palp segment II with distolateral excavation, segment II ca. $1.5 \times$ length of segment I (Fig. 2b, c)

L. glaucus

\section{Discussion}

\section{Assignment to Labiobaetis and affinities}

For the assignment of the new species to Labiobaetis, we refer to Kluge and Novikova (2014). Labiobaetis is characterised by a number of derived characters, some of which are not found in other taxa (Kluge and Novikova 2014): antennal scape sometimes with a distolateral process; maxillary palp two segmented with excavation at inner distolateral margin of segment II, excavation may be poorly developed or absent (Fig. 7g); labium with paraglossae widened and glossae diminished; labial palp segment II with distomedial protuberance (Fig. 7h). The concept of Labiobaetis is also based on additional characters, summarised and discussed in Kaltenbach and Gattolliat (2018, 2019). L. ediai sp. nov. is morphologically related to L. vinosus, sharing the absence of a distolateral process on scape, the absence of hind protoptera and six pairs of gills. The main differences are the narrow distomedial protuberance seen in labial palp segment II (broad in vinosus) (Figs $2 \mathrm{~h}, 7 \mathrm{~h}$ ), the number of spine-like setae at the dorsal margin of the fore femur (7-9 in L. ediai sp. nov.; 8-18 in L. vinosus) and the presence or absence of setae at the apex of the left mola (present in L. vinosus, absent in L. ediai sp. nov.).

\section{Labiobaetis boussoulius and L. glaucus}

Labiobaetis boussoulius was described by Gillies (1993), based on imagos, subimagos and nymphs from a single location, the Milo River near Boussoulé in Guinea. The species 
is very similar to the common and very widespread $L$. glaucus, which is also present in Guinea. Additionally, L. glaucus is known to have a very variable nymphal morphology (Lugo-Ortiz et al. 2000). Therefore, we investigated the morphology of L. boussoulius in comparison to L. glaucus: the male genitalia are indistinguishable (Gillies 1993: fig. 3; Gattolliat et al. 2018: fig. 46), both have a remarkable triangular expansion at the inner margin at the apex of segment I and the base of segment II of the gonostyli; the colouration of the male imago seems to be slightly different, according to the descriptions of Gillies 1993: p. 214 and Gattolliat et al. 2018: p. 97, but the specimen of $L$. boussoulius is from Guinea and the one of L. glaucus from Saudi Arabia and the colours may have altered by the long preservation in alcohol before their description; Gillies 1993: p. 214 indicates $0-4$ partial cross veins in the pterostigma of the male wing of L. boussoulius (Gillies 1993: fig. 1), but the male holotype has four longer cross veins not reaching the subcostal vein and one shorter cross vein, which is the same as in a male of L. glaucus from Saudi Arabia (GBIFCH00235731, GenBank MH070317); most characters of the nymph are identical (Gillies 1993: figs 4, 6-12; Gattolliat et al. 2018: figs 34-44; Lugo-Ortiz and McCafferty 1997: figs 27-50; Lugo-Ortiz et al. 2000 : figs 1-11). We notice that the maxillary palp of L. boussoulius is 2 -segmented as usually seen in Labiobaetis and not 3-segmented as shown in Gillies 1993: fig. 5. However, we identified four morphological differences in the nymphs, based on the material at our disposal: the maxillary palp of $L$. boussoulius has a more pronounced distolateral excavation at segment II than L. glaucus and segment II is longer in comparison to segment I in L. boussoulius $(1.8-1.9 \times)$ than in L. glaucus (ca. 1.5 $\times$ ) (Fig. 2a-c); the fore femur of $L$. boussoulius is usually more slender than the one of $L$. glaucus (length

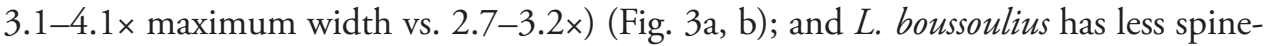
like setae at the dorsal margin of the fore femur (9-12) than L. glaucus (13-18).

Gattolliat et al. 2018 published a COI barcode of L. boussoulius (GenBank MH070309, GBIFCH00517528), which is different from the one of L. glaucus. However, the specimen is from the Ivory Coast and not from Guinea and no material is available for morphological re-investigation. Therefore, the assignment of this sequence to $L$. boussoulius remains uncertain. In conclusion, we continue to consider L. boussoulius as a valid species, based on four slight morphological differences of the nymph; but due to the known high variability of $L$. glaucus, we recommend that its status is confirmed with genetic investigations of fresh material of $L$. boussoulius from Guinea and L. glaucus from West Africa.

\section{Labiobaetis elouardi}

The morphology of Labiobaetis elouardi is very atypical for this genus: the labrum is rectangular (Fig. 8a), the setae of the submarginal arc of setae on the dorsal surface of the labrum are feathered with a broad middle part, representing a new type of seta, which was not known, so far, in Labiobaetis (Fig. 8h-j), the apex of both mandibles is cleft between incisor and kinetodontium (Fig. 8b, c), the glossae are much shorter than the paraglossae (Fig. 8d) and the paraproct has only two or three strongly devel- 
oped, marginal spines (Fig. 8f, g). Usually, in Labiobaetis, the labrum is much more subrectangular and laterally rounded, the feathered setae on the dorsal surface of the labrum have a slender middle part (Fig. 8k), incisors and kinetodontium are fused till the apex in both mandibles, the glossae are only slightly shorter than the paraglossae (except in a few species, such as the Malagasy species L. fabulosus Lugo-Ortiz \& McCafferty, 1997) and the paraproct has many and less pronounced marginal spines. The usual type of feathered setae (Fig. 8k) is present in all other Afrotropical species (Lugo-Ortiz and McCafferty 1997; Gattolliat 2001) as well as in the groups operosus and difficilis from Southeast Asia (Kaltenbach and Gattolliat 2019) and in the group orientis from New Guinea (Kaltenbach and Gattolliat 2018).

However, Labiobaetis is generally very variable in many characters and there are other species with similar characters in other regions: species of the groups vallus and sumigarensis, as well as L. moriharai Müller-Liebenau, 1984 and L. paravultuosus Kaltenbach \& Gattolliat, 2018 have a nearly rectangular labrum; an undescribed species from Borneo has similar setae dorsally on the labrum; species of the vallus group, as well as L. bakerae Kaltenbach \& Gattolliat, 2020, L. pakpak Kaltenbach \& Gattolliat, 2019, L. baganii Kaltenbach, Garces \& Gattolliat, 2020, L. delocadoi Kaltenbach, Garces \& Gattolliat, 2020, L. giselae Kaltenbach, Garces \& Gattolliat, 2020 and L. mendozai Kaltenbach, Garces \& Gattolliat, 2020, have a slight cleft between the incisor and kinetodontium; and L. paravitilis Kaltenbach \& Gattolliat, 2018 and L. fabulosus also have glossae much shorter than paraglossae. We keep L. elouardi in the concept of Labiobaetis, because of the presence of a distolateral process at the scape (Fig. 8e), a slight excavation at the inner distolateral margin of maxillary palp segment II, the large distomedial protuberance at labial palp segment II and the presence of a broad subgenital plate between the gonopods, which are all important characters of the genus. Further, Labiobaetis is known to have very different types of setae (simple, feathered, clavate, dendritic, lanceolate) forming the submarginal arc on the dorsal surface of the labrum (Kaltenbach et al. 2020: fig. 2a-e).

\section{Distribution of Labiobaetis in the Afrotropical realm}

In Kaltenbach and Gattolliat 2021, we compared the distribution of Labiobaetis species in the Afrotropical realm to Southeast Asia and New Guinea, where the majority of species live. Apart from Madagascar, where all Labiobaetis species are endemic to the Island (Gattolliat 2001), some Afrotropical species have a wide or even very wide distribution (L. glaucus, L. latus, L. potamoticus and L. vinosus), whereas most species in Southeast Asia and New Guinea are restricted to smaller regions or are endemic to an island. The reason probably lies in the high geographic complexity of the region (islands in Southeast Asia, extreme landscape structure in New Guinea), facilitating allopatric speciation and endemicity (Toussaint et al. 2013, 2014). The huge African continent is, in comparison, geographically less structured, which generally facilitates wider distributions of species. The present study confirms large distribution ranges of some Labiobaetis species in the Afrotropical realm: L. glaucus is additionally present 
in Guinea, Ivory Coast and Mali and can be considered as Panafrotropical (except Madagascar), the same probably applies for $L$. vinosus (additionally found in the Ivory Coast) and L. latus (additionally found in Guinea, Ivory Coast and Mali) and also L. piscis (additionally found in Guinea, Ivory Coast and Mali) have a very large distribution range as well. Labiobaetis gambiae seems to have a wider distribution at least in West Africa (known from Gambia, Ivory Coast and Mali) and may have been easily overlooked in other areas due to its close similarity with $L$. piscis. In contrast, L. boussoulius and L. elouardi seem to be rare and local species, while L. ediai sp. nov. is, so far, only known from the Ivory Coast, but it is not rare.

A high number of localities and different habitats have been sampled in West Africa due to the ORSTOM activities in the past (Lévêque et al. 2003), but there are still areas where no collecting has yet been carried out. Additionally, the distribution of Labiobaetis species in Africa is often much more widespread than in other regions. Therefore, we may expect a few, but not many, more species to be discovered in West Africa with further collections.

\section{Acknowledgements}

We sincerely thank Jean-Marc Elouard (France) and Edia Oi Edia (Université Nangui Abrogoua, Abidjan, Ivory Coast) for the collection of precious material and for making it available to the Museum of Zoology in Lausanne (MZL). We are also highly appreciative to Ben Price (Natural History Museum, London, Great Britain) for the essential and rapid loan of Labiobaetis type material from West Africa. Further, we are thankful to Antonio Mucciolo (University Lausanne, UNIL) for the SEM pictures and to Michel Sartori (Museum of Zoology Lausanne) for his constant interest and support for our projects and to Marion Podolak (Museum of Zoology Lausanne) for her support with lab work and preparation of the COI barcodes. Lastly, the authors are grateful to the reviewers for their valuable recommendations and comments on the manuscript.

\section{References}

Agnew JD (1961) New Baetidae (Ephem.) from South Africa. Novos Taxa Entomologicos 26: 1-9. Arimoro FO, Muller WJ (2010) Mayfly (Insecta: Ephemeroptera) community structure as an indicator of the ecological status of a stream in the Niger Delta area in Nigeria. Environmental Monitoring and Assessment 166(1-4): 581-594. https://doi.org/10.1007/s10661009-1025-3

Barber-James HM, Ferreira IS (2019) The Mayflies (Ephemeroptera) of Angola - new species and distribution records from previously unchartered waters, with a provisional species checklist. Zoosymposia 16: 124-138. 
Barber-James HM, Gattolliat J-L (2012) How well are Afrotropical mayflies known? Status of current knowledge, practical applications, and future directions. Inland Waters 2(1): 1-9. https://doi.org/10.5268/IW-2.1.447

Barber-James HM, Sartori M, Gattolliat J-L, Webb J (2013) World checklist of freshwater Ephemeroptera species. http://fada.biodiversity.be/group/show/35

Barnard KH (1932) South African may-flies (Ephemeroptera). Transactions of the Royal Society of South Africa 20(3): 201-259. https://doi.org/10.1080/00359193209518858

Cruz PV, Nieto C, Gattolliat J-L, Salles FF, Hamada N (2020) A cladistic insight into higher level classification of Baetidae (Insecta: Ephemeroptera). Systematic Entomology 2020: 1-12. https://doi.org/10.1111/syen.12446

Edia OE, Diétoa YM, Konan KF, Bony KY, Diomandé D (2015) Aquatic insect community structure in four coastal streams (Côte d'Ivoire, West Africa). Journal of Chemical, Biological and Physical Sciences, Section D 5: 1022-1037.

Elouard J-M (1986a) Éphémères d'Afrique de l'Ouest: Le genre Afromera (Ephemeridae). Revue d'Hydrobiologie Tropicale 19: 169-176.

Elouard J-M (1986b) Éphémères d'Afrique de l'Ouest: Le genre Eatonica (Ephemeridae). Revue d'Hydrobiologie Tropicale 19: 87-92.

Elouard J-M, Forge P (1978) Émergence et activité de vol nocturne de quelques espèces d'Ephéméroptères de Côte d'Ivoire. Cah. O.R.S.T.O.M. Série Hydrobiologie 12: 187-196.

Elouard J-M, Gillies MT (1989) West African Ephemeroptera. The genus Machadorythus (Tricorythidae). Aquatic Insects 11(1): 1-10. https://doi.org/10.1080/01650428909361340

Elouard J-M, Hideux P (1991) Mayflies of West Africa. Thraulobaetodes, an atypical new genus of crawling Baetidae. In: Alba-Tercedor J, Sanchez-Ortega A (Eds) Overview and Strategies of Ephemeroptera and Plecoptera, Sandhill Crane Press, Gainesville, Florida, 169-174.

Elouard J-M, Gillies MT, Wuillot J (1990) Ephemeroptera from West Africa: The genus Pseudopannota (Baetidae). Revue d'Hydrobiologie Tropicale 23: 27-39.

Folmer O, Black M, Hoeh W, Lutz R, Vrijenhoek R (1994) DNA primers for amplification of mitochondrial cytochrome c oxidase subunit I from diverse metazoan invertebrates. Molecular Marine Biology and Biotechnology 3: 294-299. http://www.mbari.org/staff/ vrijen/PDFS/Folmer_94MMBB.pdf

Gattolliat J-L (2001) Six new species of Labiobaetis Novikova \& Kluge (Ephemeroptera: Baetidae) from Madagascar with comments on the validity of the genus. Annales de Limnologie 37(2): 97-123. https://doi.org/10.1051/limn/2001013

Gattolliat J-L (2006) Bugilliesia Lugo-Ortiz and McCafferty and allied genera (Baetidae, Ephemeroptera), with emphasis on West African fauna. Mitteilungen der Schweizerische Entomologische Gesellschaft 79: 281-298.

Gattolliat J-L, Nieto C (2009) The family Baetidae (Insecta: Ephemeroptera): synthesis and future challenges. Aquatic Insects 31(sup1): 41-62. https://doi. org/10.1080/01650420902812214

Gattolliat J-L, Sartori M (2006) The mayflies of Ghana (Insecta: Ephemeroptera). Annale Historico-naturales Musei Nationalis Hungarici 98: 5-28. 
Gattolliat J-L, Kondratieff BC, Kaltenbach T, Al Dhafer HM (2018) Labiobaetis from the Kingdom of Saudi Arabia (Insecta: Ephemeroptera: Baetidae). ZooKeys 774: 77-104. https://doi.org/10.3897/zookeys.774.25273

Gillies MT (1980) An introduction to the study of Cloeon Leach (Baetidae, Ephemeroptera) in West Africa. Bulletin de l'Institut Français d'Afrique Noire 42: 135-156.

Gillies MT (1989) Occurrence of Rhithrocloeon (Baetidae: Ephemeroptera) in West Africa. Revue d'Hydrobiologie Tropicale 22: 287-288.

Gillies MT (1993) Descriptions of some Afrotropical Baetidae (Ephemeroptera) II. Baetis Leach, s.l., West African species. Aquatic Insects 15(4): 213-223. https://doi. org/10.1080/01650429309361522

Gillies MT (1994) Descriptions of some Afrotropical Baetidae (Ephemeroptera). II. Baetis Leach, s.l., East African species. Aquatic Insects 16(2): 105-118. https://doi. org/10.1080/01650429409361543

Gillies MT (1997) A new species of Procloeon Bengtsson from the forest zone of West Africa (Ephemeroptera, Baetidae). Entomologist's Monthly Magazine 133: 247-250.

Gillies MT, Elouard J-M (1990) The mayfly-mussel association, a new example from the River Niger basin. In: Campbell IC (Ed.) Mayflies and Stoneflies: Life histories and biology. Kluwer Academic Publishers, Dordrecht, 289-297. https://doi.org/10.1007/978-94-009-2397-3_35

Harrison AD, Hynes HBN (1988) Benthic fauna of Ethiopian mountain streams and rivers. Archiv für Hydrobiologie Supplement 81: 1-36.

Hubbard MD (1995) Towards a standard methodology for the description of mayflies (Ephemeroptera). In: Corkum LD, Ciborowski JJH (Eds) Current Directions in Research on Ephemeroptera. Canadian Scholar's Press, Toronto, 361-369.

Jacobus LM, Macadam CR, Sartori M (2019) Mayflies (Ephemeroptera) and their contributions to ecosystem services. Insects 10(6): 1-26. https://doi.org/10.3390/insects10060170

Kaltenbach T, Gattolliat J-L (2018) The incredible diversity of Labiobaetis Novikova \& Kluge in New Guinea revealed by integrative taxonomy (Ephemeroptera, Baetidae). ZooKeys 804: 1-136. https://doi.org/10.3897/zookeys.804.28988

Kaltenbach T, Gattolliat J-L (2019) The tremendous diversity of Labiobaetis Novikova \& Kluge in Indonesia (Ephemeroptera, Baetidae). ZooKeys 895: 1-117. https://doi.org/10.3897/ zookeys.895.38576

Kaltenbach T, Gattolliat J-L (2020a) Labiobaetis Novikova \& Kluge in Borneo (Ephemeroptera, Baetidae). ZooKeys 914: 43-79. https://doi.org/10.3897/zookeys.914.47067

Kaltenbach T, Gattolliat J-L (2020b) Pedicelliops gen. nov., a new genus from West Africa with striking antennae (Ephemeroptera, Baetidae). African Invertebrates 61: 119-135. https:// doi.org/10.3897/afrinvertebr.61.59354

Kaltenbach T, Gattolliat J-L (2021) Labiobaetis Novikova \& Kluge in Ethiopia (Ephemeroptera, Baetidae), with description of a new species. African Invertebrates 62(1): 231-255. https://doi.org/10.3897/afrinvertebr.62.62029

Kaltenbach T, Garces JM, Gattolliat J-L (2020) The success story of Labiobaetis Novikova \& Kluge in the Philippines (Ephemeroptera, Baetidae), with description of 18 new species. ZooKeys 1002: 1-114. https://doi.org/10.3897/zookeys.1002.58017

Kluge NJ (2004) The Phylogenetic System of Ephemeroptera. Academic Publishers, Dordrecht, 442 pp. https://doi.org/10.1007/978-94-007-0872-3 
Kluge NJ (2021) Ephemeroptera of the world. http://www.insecta.bio.spbu.ru [retrieved 04.02.2021]

Kluge NJ, Novikova EA (2014) Systematics of Indobaetis Müller-Liebenau \& Morihara, 1982, and related implications for some other Baetidae genera (Ephemeroptera). Zootaxa 3835(2): 209-236. https://doi.org/10.11646/zootaxa.3835.2.3

Kluge NJ, Novikova EA (2016) New tribe Labiobaetini tribus n., redefinition of Pseudopannota Waltz \& McCafferty 1987 and descriptions of new and little known species from Zambia and Uganda. Zootaxa 4169(1): 1-43. https://doi.org/10.11646/zootaxa.4169.1.1

Kopelke J-P (1980) Ephemeroptera aus der Emergenz des zentralafrikanischen Bergbaches Kalengo (Zaire) Teil I: Baetidae. Entomologische Abhandlungen 43: 99-129.

Lévêque C, Hougard JM, Resh V, Statzner B, Yameogo L (2003) Freshwater ecology and biodiversity in the tropics: What did we learn from 30 years of onchocerciasis control and the associated biomonitoring of West African rivers? Hydrobiologia 500(1-3): 23-49. https:// doi.org/10.1023/A:1024660017077

Lugo-Ortiz CR, de Moor FC (2000) Pseudocloeon aquacidum: a new subjective synonym of $P$. latum (Ephemeroptera: Baetidae). Entomological News 111: 380-381.

Lugo-Ortiz CR, McCafferty WP (1997) Labiobaetis Novikova \& Kluge (Ephemeroptera: Baetidae) from the Afrotropical region. African Entomology 5: 241-260.

Lugo-Ortiz CR, de Moor FC, Barber-James HM (2000) A taxonomic and ecological review of Pseudocloeon glaucum (Agnew) (Ephemeroptera: Baetidae). African Entomology 8: 281-288.

Ogden TH, Whiting MF (2005) Phylogeny of Ephemeroptera (mayflies) based on molecular evidence. Molecular Phylogenetics and Evolution 37(3): 625-643. https://doi. org/10.1016/j.ympev.2005.08.008

Ogden TH, Gattolliat J-L, Sartori M, Staniczek AH, Soldán T, Whiting MF (2009) Towards a new paradigm in mayfly phylogeny (Ephemeroptera): Combined analysis of morphological and molecular data. Systematic Entomology 34(4): 616-634. https://doi.org/10.1111/ j.1365-3113.2009.00488.x

Ogden TH, Breinholt JW, Bybee SM, Miller DB, Sartori M, Shiozawa D, Whiting MF (2019) Mayfly phylogenomics: Initial evaluation of anchored hybrid enrichement data for the order Ephemeroptera. Zoosymposia 16: 167-181.

Sanger F, Nicklen S, Coulson AR (1977) DNA sequencing with chain-terminating inhibitors. Proceedings of the National Academy of Sciences of the United States of America 74(12): 5463-5467. https://doi.org/10.1073/pnas.74.12.5463

Sartori M, Brittain JE (2015) Order Ephemeroptera. In: Thorp J, Rogers DC (Eds) Ecology and General Biology: Thorp and Corvich's Freshwater Invertebrates. Academic Press, 873-891. https://doi.org/10.1016/B978-0-12-385026-3.00034-6

Shi W, Tong X (2014) The genus Labiobaetis (Ephemeroptera: Baetidae) in China, with description of a new species. Zootaxa 3815: 397-408. https://doi.org/10.11646/zootaxa.3815.3.5

Shorthouse DP (2010) SimpleMappr, an online tool to produce publication-quality point maps. [Retrieved from https://www.simplemappr.net; accessed February 10, 2021]

Tahmasebi J, Siahkalroudi SY, Kheradpir N (2020) A scientific report on Ephemeroptera of Jajrood river, Northern Iran. Journal of Wildlife and Biodiversity 4: 1-8. https://doi. org/10.22120/jwb.2020.124737.1130 
Tofilski A (2018) DKey software for editing and browsing dichotomous keys. ZooKeys 735: 131-140. https://doi.org/10.3897/zookeys.735.21412

Toussaint EA, Sagata K, Surbakti S, Hendrich L, Balke M (2013) Australasian sky islands act as a diversity pump facilitating peripheral speciation and complex reversal from narrow endemic to widespread ecological supertramp. Ecology and Evolution 3(4): 1031-1049. https://doi.org/10.1002/ece3.517

Toussaint EA, Hall R, Monaghan MT, Sagata K, Ibalim S, Shaverdo HV, Vogler AP, Pons J, Balke M (2014) The towering orogeny of New Guinea as a trigger for arthropod megadiversity. Nature Communications 5(1): 4001-4010. https://doi.org/10.1038/ncomms5001

Vuataz L, Sartori M, Wagner A, Monaghan MT (2011) Toward a DNA taxonomy of Alpine Rhithrogena (Ephemeroptera: Heptagenidae) using a mixed Yule-Coalescent Analysis of mitochondrial and nuclear DNA. PLoS ONE 6(5): 1-11. https://doi.org/10.1371/journal.pone.0019728

Wuillot J, Gillies MT (1993a) Cheleocloeon, a new genus of Baetidae (Ephemeroptera) from West Africa. Revue d'Hydrobiologie Tropicale 26: 213-217.

Wuillot J, Gillies MT (1993b) New species of Afroptilum (Baetidae, Ephemeroptera) from West Africa. Revue d'Hydrobiologie Tropicale 26: 269-277.

Wuillot J, Gillies MT (1994) Dicentroptilum, a new genus of mayflies (Baetidae, Ephemeroptera) fromAfrica.AquaticInsects 16(3):133-140.https://doi.org/10.1080/01650429409361547 